No. 18

BOOK REVIEW DEPT.

Pacific Coast Journal of Nursing

721 NEW CALL BLDG.

ises Sof thite

Please review this book and return, if possible, on or

be!
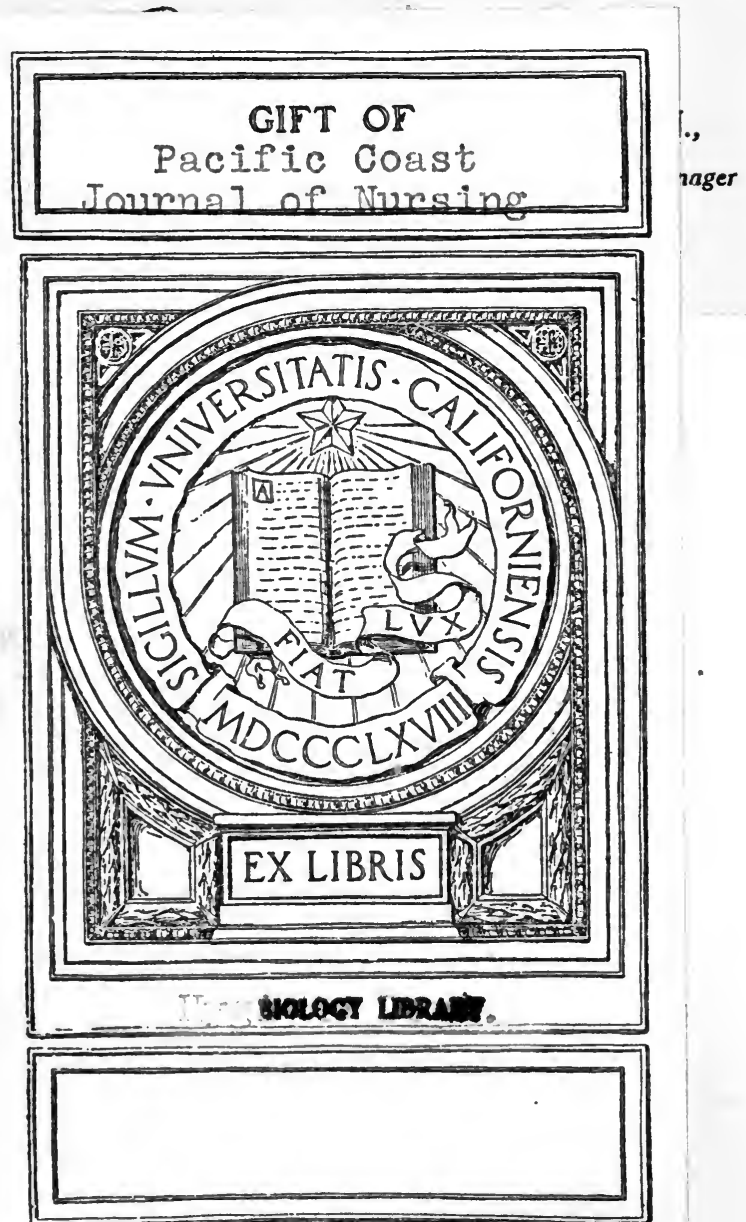


\section{THE PACIFIC COAST JOURIAL (jF NURSING}

No. $/ 8$

PROPERTY OF

The California State Nurses' Association, Inc.

\section{JOURNAL LIBRARY}

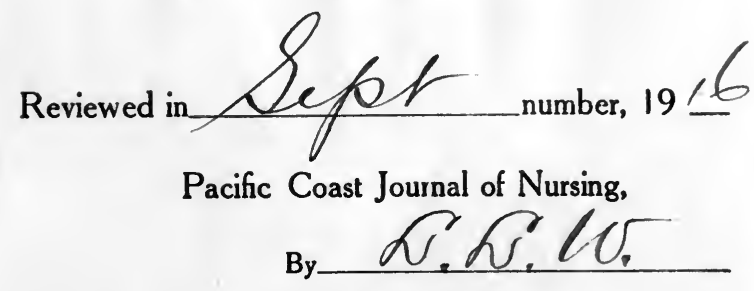

Not to be taken from Library 
Digitized by the Internet Archive in 2007 with funding from Microsoft Corporation 


\title{
ORTHOPEDIC SURGERY FOR NURSES
}

\author{
BY \\ JOHN McWILLIAMS BERRY, M. D. \\ CLINICAL PROFESSOR OF ORTHCEDICS AND RÖNTGENOLOGY AT THE \\ ALBANY MEDICAL COLLEGE, NEW YORK
}

ILLUSTRATED

PHILADELPHIA AND LONDON

W. B. SAUNDERS COMPANY 1916 


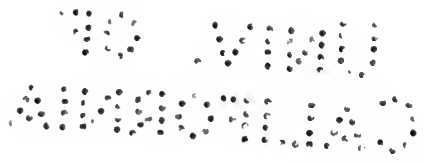

BIOLOGY

LIBF:AY

\title{
GIFT PAOIFIO COAST JOURNAL OF IULR INE TO HYGEINE DEPT
}

\author{
Copyright, 1916, by W. B. Saunders Company
}

PRINTED IN AMERICA 


\section{PREFACE}

Tre chief asset of a trained nurse is to possess a thorough knowledge of the principles and practice of nursing; but, in addition, she should understand enough about medical and surgical subjects to make her own work comprehensive and give intelligent advice to inquiring friends and patients. In this latter connection it is important that a nurse should understand something about Orthopedic Surgery.

A knowledge of how to recognize orthopedic deformities at an early stage; the danger that exists in not recognizing them; the possibilities of cure; and the sad results of lack of proper treatment would be of advantage to all parents and individuals interested in children, and such knowledge should be expected of all trained nurses.

The object of "Orthopedic Surgery for Nurses" is not so much to supply nurses with a text-book, in the sense of a medical student's text-book, as to give them a book which will discuss clearly and simply the recognition, diagnosis, prognosis and treatment of the more common and important orthopedic deformities. In order to elucidate and emphasize the text many free-hand outline illustrations have been added.

I wish to express my thanks to Mrs. Ralph B. Post, formerly Supervising Nurse at the Albany Hospital, for her criticism of the work, and to Dr. William P. Howard for the free hand illustrations.

Albany, N. Y.,

John McWilitiams BerRy.

June, 1916. 



\section{CONTENTS}

PAGE

IŃTRODUCTION

\section{CHAPTER I}

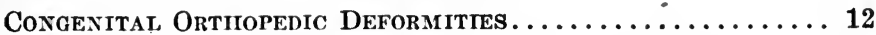

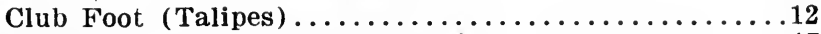

Congenital Dislocation of the Hip...............

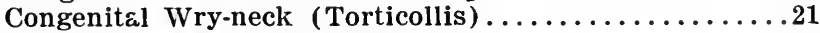

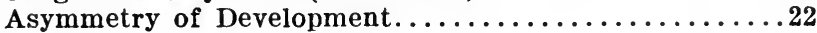

CHAPTER II

Acquiren Deformities Caused by Disease............24

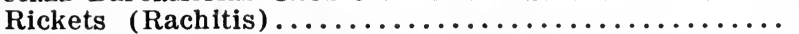

Infantile Paralysis (Anterior Poliomyelitis)........29

Birth Palsy (Spastic Paralysis, Little's Disease).......31

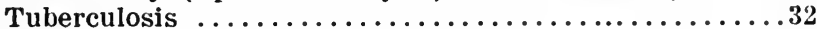

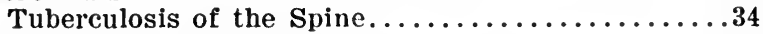

Tuberculosis of the Hip..................

Tuberculosis of the Knee and Other Joints........37

Chronic Deforming Arthritis...............41

Senile Osteo-arthritis...................

Rheumatoid Arthritis.................42

\section{CHAPTER III}

Regional Deformities....................44

The Neck.......................... 44

Acquired Wry-neck................... 44

Cervical Rib......................44

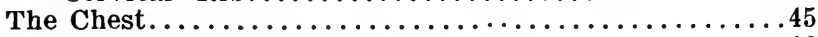

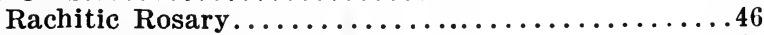

Harrison's Groove....................

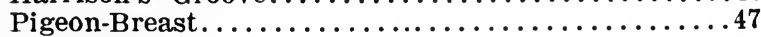

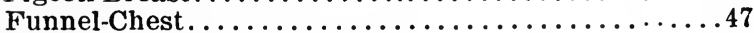

The Spine......................... 47

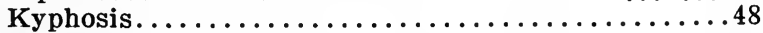

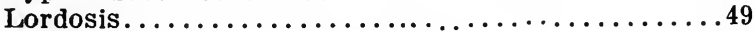

Scoliosis..........................50

Spondylitis Deformans................53 
The ShE

The Shoulder.......................

Congenital Dislocation.................. 54

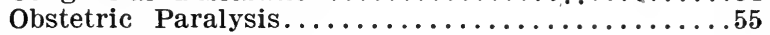

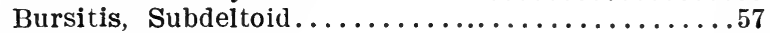

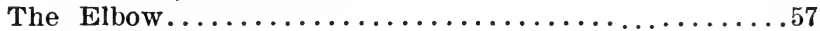

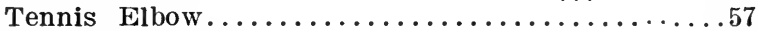

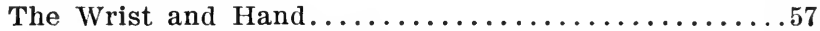

Congenital Deformities................. 57

Volkmann's Ischemic Paralysis.............. 58

Ganglion........................ 59

The Fingers............................ 59

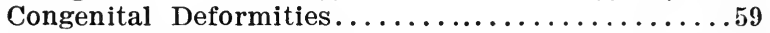

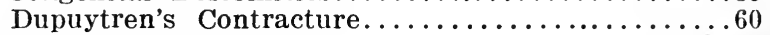

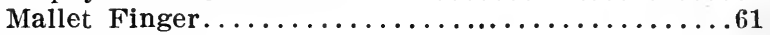

Trigger Finger......................61

CHAPTER IV

Regional Deformities (Continued) .............62

The Pelvis..........................62

Sacro-Iliac Strain..................62

The Hip............................63

The Knee.........................63

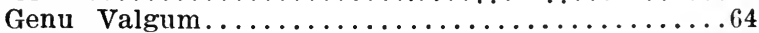

Genu Varum........................64

Genu Recurvatum...................65

Anterior Bowing of the Legs..............65

Housemaid's Knee (Prepatellar Bursitis) .......66

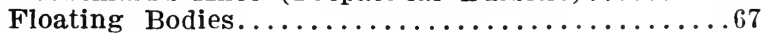

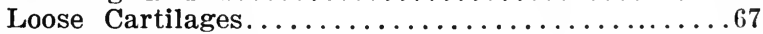

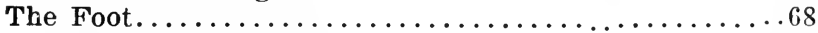

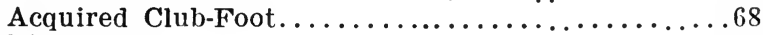

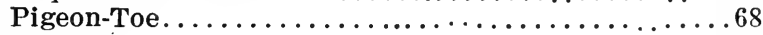

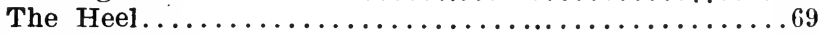

Bursitis.........................69

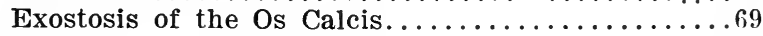

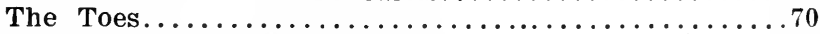

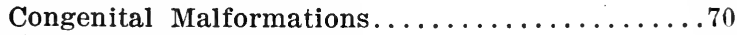

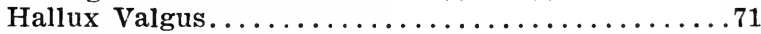

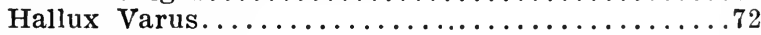

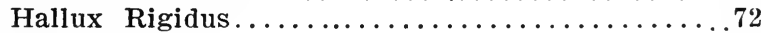

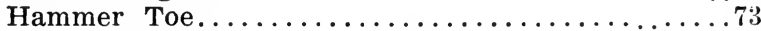

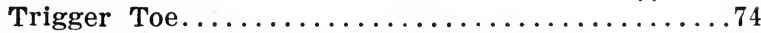

Anterior Metatarsalgia and Morton's Toe........74

WEAK FEET........................... 76

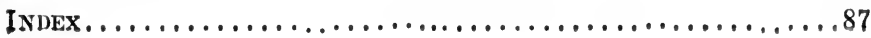




\section{ORTHOPEDIC SURGERY, FOR NURSES}

\section{INTRODUCTION}

Modern Orthopedic Surgery may be fairly described as the surgery of the deformities and disabilities of the apparatus of locomotion; the phrase, apparatus of locomotion, being used in a broad sense to include, not only the lower extremities, but also the trunk and upper extremities. Club feet, bow legs, curvature of the spine, paralytic deformities of the arm, etc., are all examples of orthopedic deformities. Hare-lip, cleft palate, hernias, etc., are deformities, but, since they have nothing to do with the apparatus of locomotion, they would not be considered as within the province of Orthopedic Surgery.

The deformities of the apparatus of locomotion may be divided into two main classes: congenital and acquired. Congenital Deformities are present at birth and can be recognized at that time or become apparent soon after. Their causes are to be sought for in the conditions governing intra-uterine life. Acquired Deformities develop after birth and are the result of diseases, strain and overloading of the body framework, contractions, etc. 


\section{CHAPTER I}

\section{CONGENITAL ORTHOPEDIC DEFORMITIES}

The congenital orthopedic deformities include: clubbing of the extremities, of which club foot is the most important; congenital dislocation of various joints, especially the hip; wry-neck; asymmetrical development; missing bones, supernumerary bones, malformed or misplaced bones, etc.

\section{CLUB FOOT-TALIPES}

Club Foot or Talipes, which is the correct medical term, is a deformity in which there is an abnormality in the anatomical relation of the foot to the leg or of one part of the foot to another part. It has been observed that club foot sometimes runs in families, being transmitted through the male side. The deformity can take place in any direction that the foot can move. Thus there may be:

Deformity (the foot turned) downward-talipes equinus (Fig. 1).

Deformity (the foot turned) upward-talipes calcaneus (Fig. 2).

Deformity (the foot turned) inward-talipes varus (Fig. 3). 


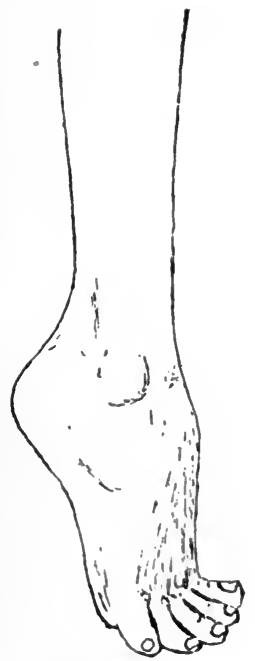

Fig. 1.

Talipes equinus.

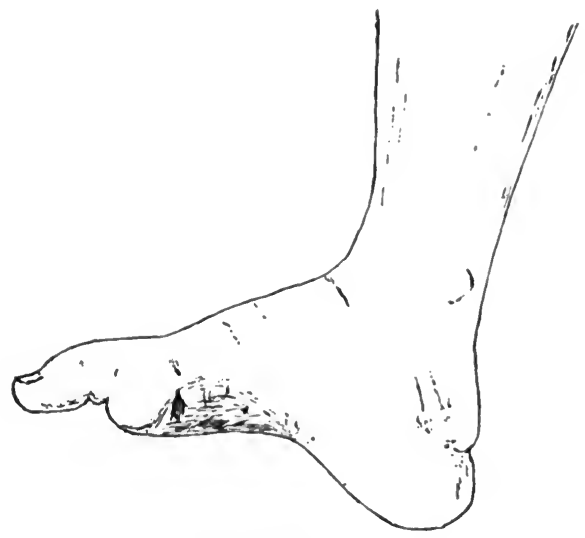

Fig. 2.

Talipes calcaneus.

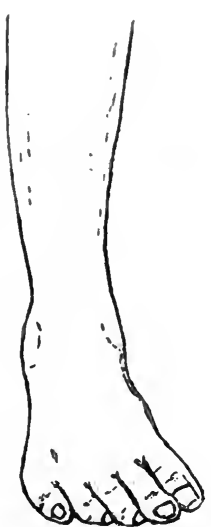

Fig. 3.

Tallpes varus.

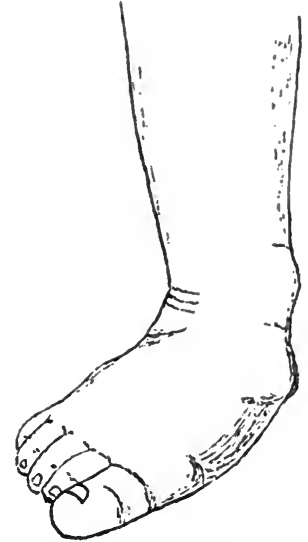

Fig. 4.

Tallpes valgus. 
Deformity (the foot turned outward)-talipes valgus (Fig. 4).

Combinations of deformities may be present, in fact they usually are. The most common form, and the one usually referred to by the term club foot, is a combination of downward and inward deformity or, to designate it by the correct medical term, Talipes Equino-Varus (Fig. 5).

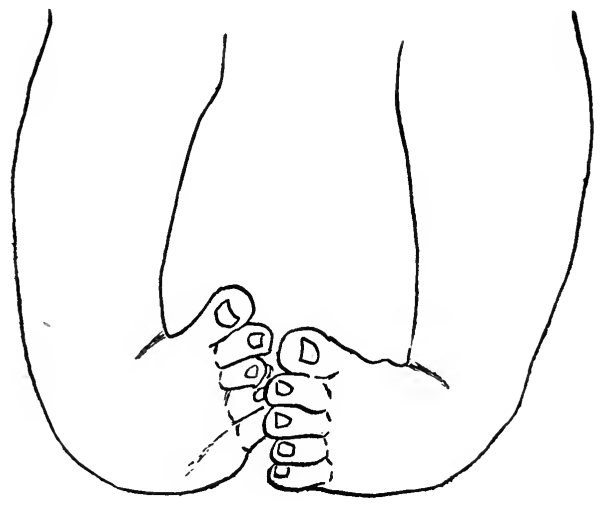

Fig. 5.

Club Foot-Talipes equino-varus.

Congenital club foot is usually easily recognized. In a new-born baby suffering from equino-varus the foot is turned downward and inward, and is rotated so that the sole of the foot faces inward or, in extreme cases, almost upward (Fig. 5). Sometimes a new- 
born baby holds its feet in a position which gives the impression of deformity, but, if its feet can be easily turned into a normal position, no club foot is present. $\Lambda$ simple test in some of these doubtful cases is to warm the infant thoroughly by placing it near a fire; if the child has no deformity it will flex the thighs on the abdomen, the legs on the thighs, and turn the feet outward.

The symptoms of club foot are those of a progressing deformity, making walking more and more difficult. The soft tissues, such as ligaments and fascix, become contracted and the bones gradually become distorted. The foot is turned more and more into a deformed position until walking becomes almost impossible. In the more common form of club foot (equino-varus), in addition to the turning of the foot, there may be a rotation in of the whole leg, causing an exaggerated pigeon toe walk, one foot having to be lifted over the other (Fig. 6). The normal development of the foot and leg is interfered with and, in unilateral cases, the affected extremity is noticeably the smaller. There is no pain except for the pain associated with corns and callosities, which develop on the feet as the result of their peculiar position.

The treatment of club foot should begin almost as soon as the child is born and should be continued until the deformity is overcorrected and there is no tendency to recurrence. This usually means a long period of treatment and supervision, because the deformity is very resistant to treatment and has a marked tendency to 
recur. Half cures are no cures at all. Many cases seem to be cured for a time, but, owing to a want of care or to negligence a relapse takes place. The possibility of a relapse exists so long as growth is going on; with the strength and stability of the tissues, which follows the attainment of full growth, the danger of increase or recurrence of deformity disappears. This is true of many deformities other than club feet.

The longer a case goes

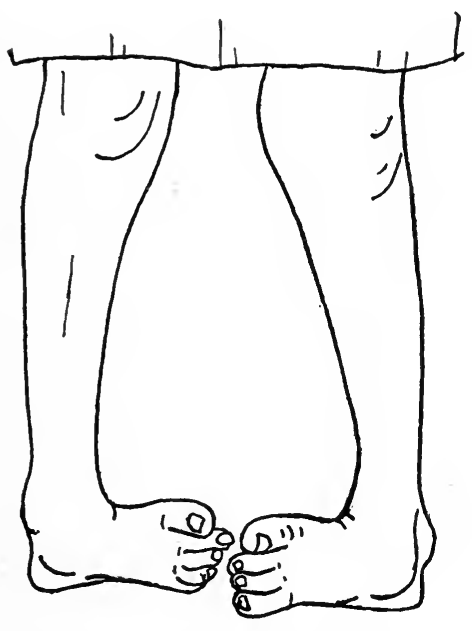

Fig. 6.

Neglected club foot (After Whitman).

without treatment the $\mathrm{m}$ or e difficult is its cure; therefore, the prime essential of succ e s sful treatment is early recognition of the deformity. In very mild cases all that may be required is corrective manipulation by the nurse or parent several times a day. In more severe cases adhesive strapping or a light plaster-of-Paris cast may be $r$ equired to hold the foot in a correct position after the manipulation. Resistant cases and cases seen at a later date, when the deformity has become more fixed, require manipulative correction under an anesthetic. This correction may be with or without subcutaneous cutting 
of contracted tendons and fascix, and is followed by retention in a plaster-of-Paris dressing. Neglected cases require severe operative measures on the contracted tissues and deformed bones, and a perfectly formed foot can never be obtained.

\section{CONGENITAL DISLOCATION OF THE HIP}

Congenital Dislocation of the Hip is a deformity in which the head of the femur is partially or completely displaced from its socket (the acetabulum) (Fig. 7). It may be present on one or both sides of the body, and occurs more frequently in girls than in boys. It is not a very common deformity, but it is common enough to cause very unfortunate mistakes in diagnosis at times.

The deformity may not be recognized at birth and only becomes apparent when the child tries to walk. Children with congenital dislocation of the hip or hips do not walk as early as most children; there is usually a prominence of the affected hip or hips backward, and when the child does walk, the gait is abnormal.

Symptoms.-As has been said, the symptoms may not show themselves until the child begins to walk. If the dislocation is only on one side, the leg on that side is shorter (Fig. 8), and the child walks with a marked limp. If, however, the dislocation is present on both sides, the child walks with a characteristic "duck like" waddle. The hips are very prominent behind and there is a marked bending forward of the lower spine (lordosis) (Fig. 9). The child tires easily and may complain of pain in the hips. 
The course of untreated congenital dislocation of the hip is a progressive deformity and weakness, which in time may make walking almost impossible.

Treatment.-There are two well-known methods of
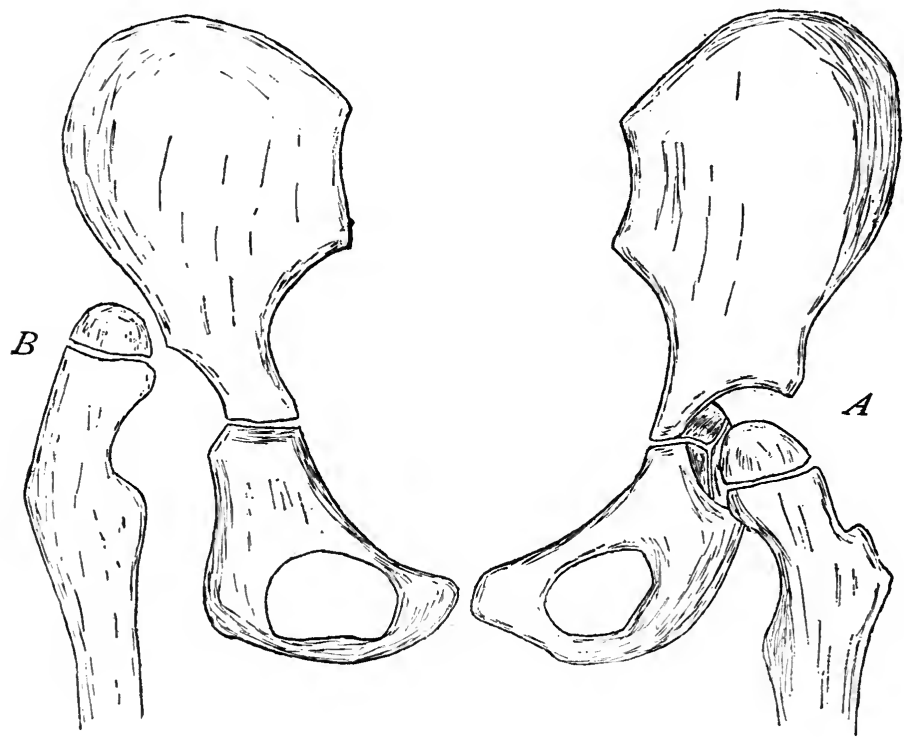

Fig. 7.

Tracing of an X-Ray picture of congenital dislocation of the hip. (A) is the normal hip. (B) is the dislocated hip.

treatment in congenital dislocation of the hip: one is known as the open method and the other as the bloodless method. The latter was made famous by Dr. Lorenz of Vienna, and is generally known as the Lorenz method. In the open or operative method, the hip joint 
is opened, the acetabulum is scraped out and the head of the femur is put in place. This method is more or less dangerous and is not generally used. In the Lorenz

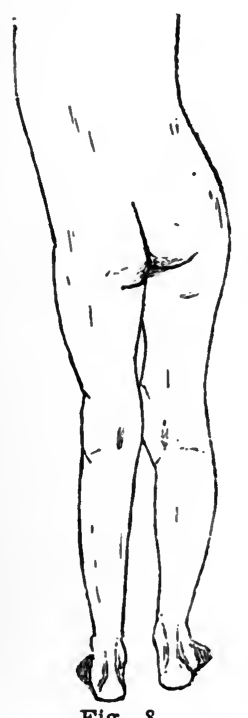

Fig. 8.

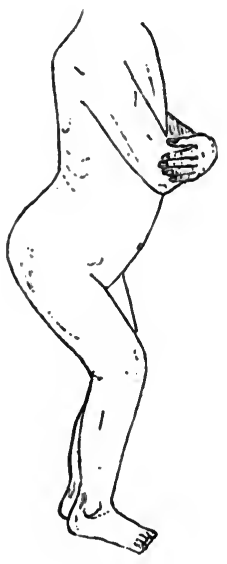

Fig. 9.

Characteristic attitude in double congenital dislocation of the hip. titude and shortening of leg in unilateral congenital dislocation of the hip (Left). In the drawing it looks as if the right leg was the shorter of the two, but this is due to the fact that the pelvis is tilted.

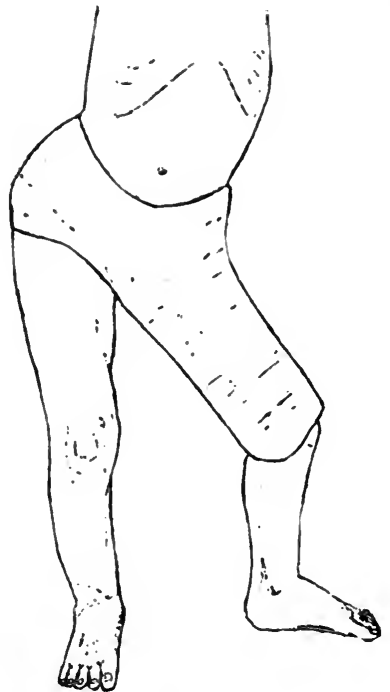

Fig. 10.

Plaster-of-Paris castFrog position-Unilateral congenital dislocation of the hip.

method, the displaced head of the femur is manipulated back into place and held in position by a plaster cast until it has worn a more perfect socket for itself. The 
position in which the leg is placed to accomplish this is known as the "Frog Position" (Figs. 10, 11). It usually takes one or more years to cure a case of con-

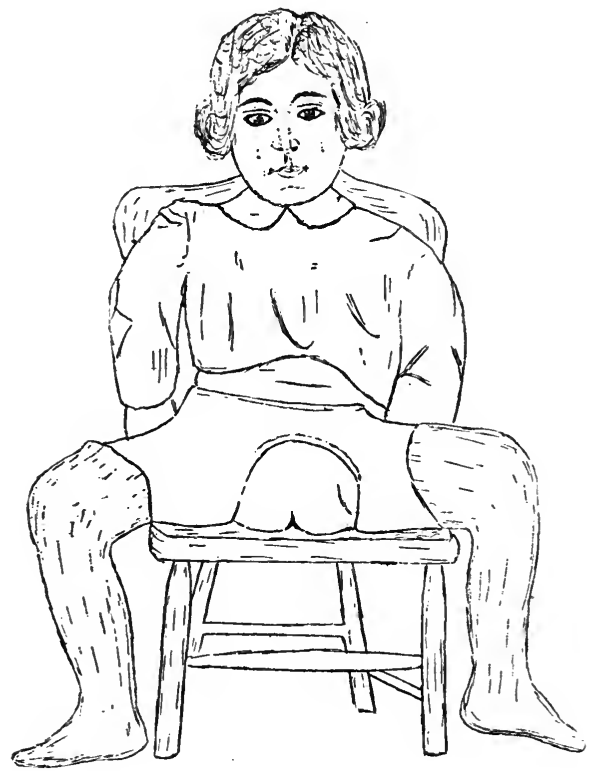

Fig. 11. Plaster-of-Paris cast-Frog position-Double congenital
dislocation of the hip (After Whitman).

- genital dislocation of the hip and, if the treatment is not started early cnough, a cure is impossible. It is very difficult or impossible to cure congenital dislocation of the hip in a child more than eight years old. 


\section{CONGENITAL WRY-NECK-TORTICOLLIS}

In Congenital Wry-Neck or Torticollis, the child is born with the head held to one side, rotated somewhat to the opposite side and tilted back (Fig. 12). The

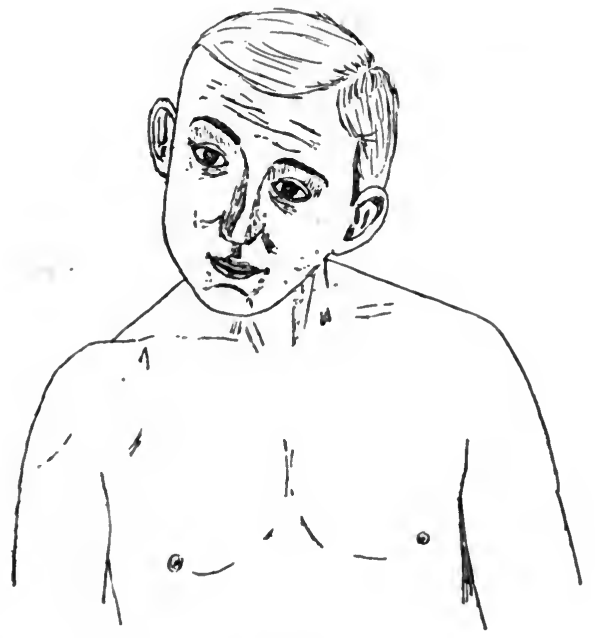

Fig. 12.

Wry-Neck, left sided.

position is due to a contraction of the sterno-cleido mastoid muscle, the exact cause of which is in dispute.

In mild cases and in cases recognized early corrective manipulation may be sufficient to effect a cure; but, in resistant and neglected cases it is necessary to divide. the tendon of the muscle, overcorrect the deformity and put on a plaster-of-Paris dressing, including the head and chest (Fig. 13). Close supervision is neces- 
sary for a long time to see that recurrence does not take place.

\section{ASYMMETRY OF DEVELOPMENT}

Comparatively few individuals are born perfectly formed; one leg may be a little longer than the other,

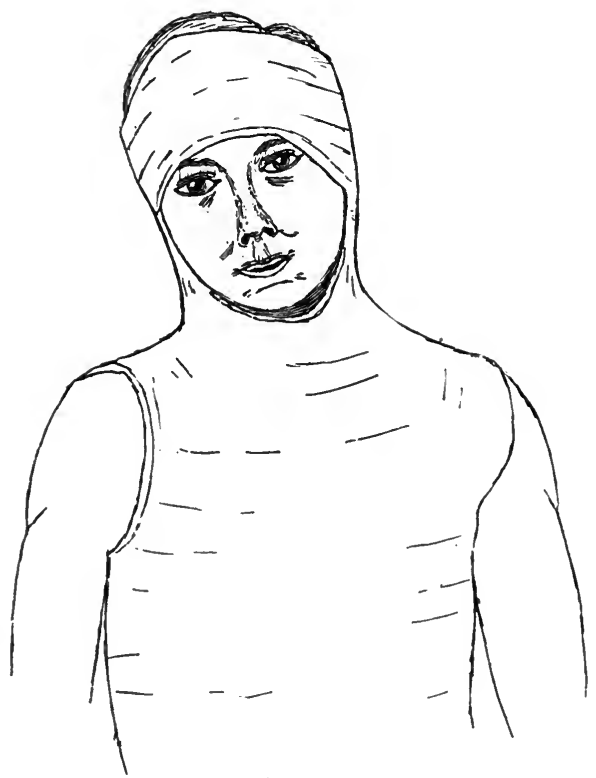

Fig. 13.

Wry-Neck overcorrected and in Cast.

one arm a little larger than the other, etc. Sometimes the asymmetry affects one whole side of the body, so that the individual seems to be a combination of two bodies of unequal size (Fig. 14). Individuals with asymmetrical development are usually perfectly well 
and suffer no inconvenience other than possibly strains from the unequal length of the limbs, which in some cases may cause a curvature of the spine.

Missing Bones and Supernumerary Bones or Abnormally Placed or Formed Bones are frequently the cause of characteristic deformities. The deformities are usually easily recognized, but it is not always possible to cure them.

There are many congenital orthoperlic deformities other than those here discussed, but it is not necessary that a trained nurse should know all of the congenital deformities or very much about any of them. She should understand, however, that there are such deformities, that they are sometimes difficult to recognize, and that, if they are not recognized early, they may become incurable. She should, therefore, appreciate the fact that, any abnormality in a child should not be overlooked or neglected. For example, a

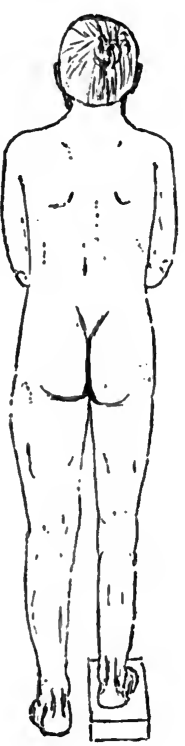

Fig. 14. child who constantly holds its feet in asymmetrical dea peculiar position, who walks with a limp or holds the head on one side, may be suffering from club feet, congenital dislocation of the hip or wry-neck as the case may be. Such cases should always be investigated and never passed over with the remark so frequently made: "he (or she) will probably outgrow it." 


\section{CHAPTER II}

\section{ACQUIRED DEFORMITIES CAUSED BY DISEASE}

The diseases which commonly cause orthopedic deformities are: rickets, infantile paralysis, birth palsy, tuberculosis, chronic deforming arthritis, etc.

\section{RICKETS}

Rickets or Rachitis is a constitutional disorder which occurs chiefly in children, is associated with malnutrition and manifests itself largely by changes in the bones.

Causes.-The chief contributing causes of rickets are supposed to be improper food and lack of sunlight and fresh air. The disease is very common in the poorer class of Italian children who are brought up largely on cereals. It is also common among negro children, but is not, however, confined to the children of the poor, since improper feeding may occur among all classes. For example, a marked case of rickets developed in the child of well-to-do people because, in the effort to bring the baby up in a perfectly healthy way, all the milk that the baby took was boiled. The child's mother was under the impression that the baby should be fed only on sterilized milk and that boiling was the way to sterilize it. 
Foods containing an excess of stareh and too little fat are supposed to be conducive to rickets. Babies brought up on condensed milk are apt to be rickety, as are also the babies brought up on proprietary foods. Cereals, boiled milk, condensed milk and proprietary foods do not always contain the proper ingredients for perfect growth, despite the fact that some children thrive on them. The whole subject of infant feeding is a most important one and is too often neglected. Further discussion of the subject is not within the provinee of this work, but it may be well, at this time, to impress upon the trained nurse its important bearing on the future welfare of babies.

In all cases of rickets there is an abnormal growth of bone. Bones are at first composed entirely of cartilage, and become hard and firm by the dcposition of lime salts. This process takes place prineipally at the growing ends (the epiphyses) and beneath the periosteum, and is known as ossification. In rickets the normal process is

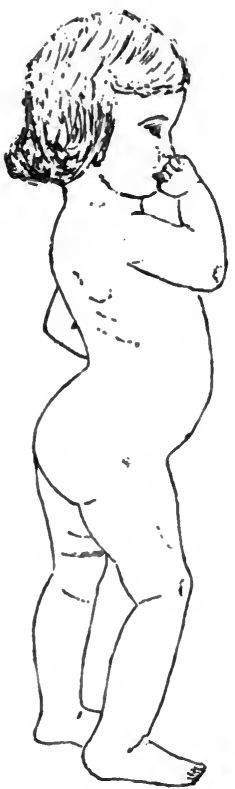

Fig. 15.

Rickets.-En. larged abdomen and lordosis (Bradford and Lovet $t$ ). interfered with, and the ossification is irregular or partially absent; one of the results of this is an abnormal softness of the bones.

Symptoms.-The symptoms of rickets are as follows: 
There is a profuse sweating of the head. The anterior fontanelle remains open (it should close at eighteen months). The forehead is prominent and square. The abdomen is enlarged, due in part to an enlargement of the liver, and when the child stands there is a

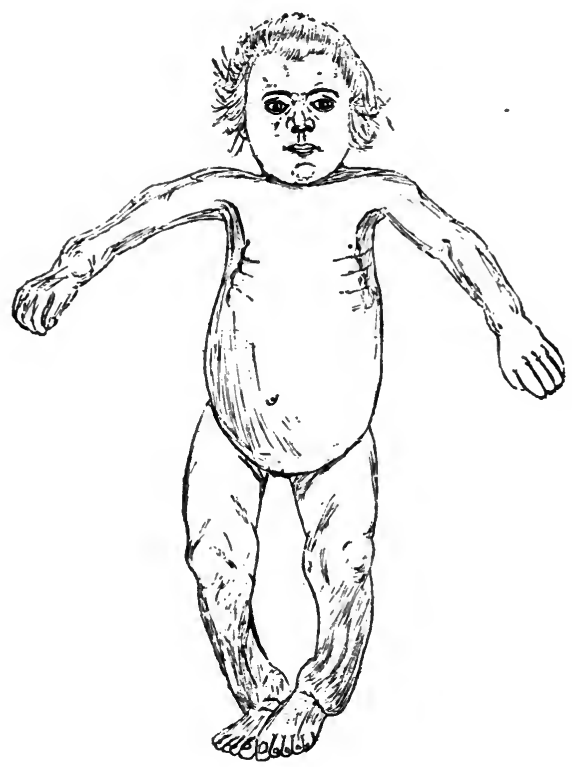

Fig. 16.

General Rickets.-Note the beading of the ribs (rickety rosary) - the enlarged abdomen-the enlarged epiphyses at the wrist and ankle-the bowing of the legs.

marked forward bending (lordosis) of the spine (Fig. 15). The growing ends of the bones (the epiphyses) are enlarged; this is noticeable especially at the wrists and ankles. The ribs are beaded (rickety rosary). 
The long bones are bowed (Fig. 16). There is delayed dentition and the child does not walk as early as it should. The spine may be weak and the child is unable to sit up straight (Fig. 17). A normal baby should hold its head up and begin to use its hands at three

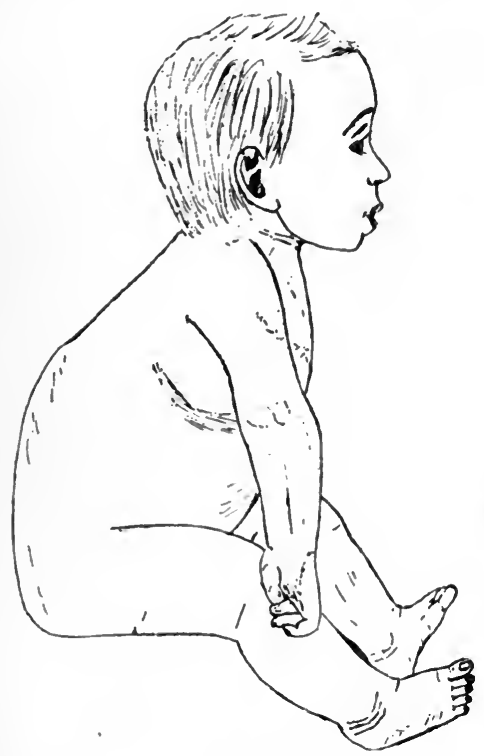

Fig. 17.

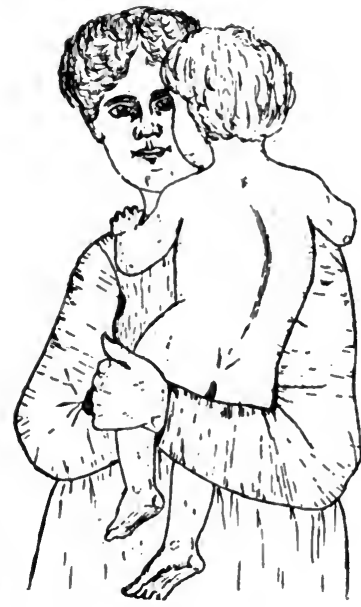

Fig. 18.

Postural deformity in spinal rickets.

Spinai rickets.-Kyphosis.

months, sit up at six months, creep at eight months, walk and say a few words at fourteen months. If a child cannot do these things, or if dentition is delayed, look for symptoms of rickets.

The abnormal softness of the bones leads to various 
deformities, the most pronounced of which are in the chest and legs. These will be discussed under regional deformities.

Treatment.-The essential treatment in the active stage of the disease is proper feeding, sunlight and fresh

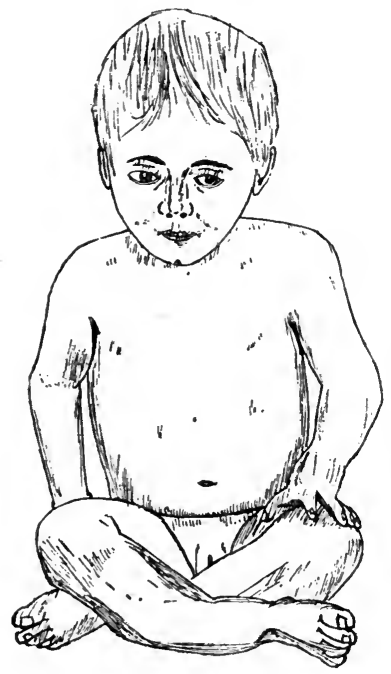

Fig. 19.

Postural deformity in rickets, bow legs.

air. Rest and a tonic treatment are also usually indicated. If the spine is weak the child should be placed on a firm mattress, otherwise the weight of the body tends to cause curvature (Fig. 18). Sometimes the weight of the limbs hanging over the arm of the nurse, if the child is carried a great deal, causes them to bow forward; at other times the way in which the child sits tends to cause bowing (Fig. 19). Older children with acute rickets should not be urged to stand and walk, since this will tend

to increase the deformity of the legs.

The disease is usually self limiting and quiets down in a few months or years, at which time, if the resulting deformities are pronounced, they can be corrected by operation. 


\section{INFANTILE PARALYSIS}

Infantile paralysis or anterior poliomyelitis is an infectious epidemic disease which chiefly affects children. Only comparatively recently it has been discovered that the disease is caused by a germ. The germ excites an acute inflammation of the spinal cord, destroying or injuring nerve cells, and thereby causing a paralysis of the muscles controlled by these cells.

Symptoms. - The initial symptoms are those of an acute fever and may be very mild, the child simply complaining of not feeling well or perhaps has a headache on going to bed. In the morning the child may be found paralyzed. On the other hand, the symptoms may be much more severe and the child be ill for several days with a high fever and convulsions.

The paralysis which occurs is of the flaccid type, $i$. e., the affected parts hang limp and lifeless. The original paralysis usually clears up to a considerable extent; for example, both legs and both arms may be affected at first and later recovery may take place except in one leg. The child is almost always left with a certain amount of paralysis which, unless properly treated, becomes more and more deforming. This is due to the fact that contractures take place.

Contractures occur from the following reasons: Normally the muscles are in a condition of tone, $i$. e., slightly contracted. They are also arranged in sets opposed to each other. For example, one set of muscles flexes the forearm upon the arm, and this set of muscles 
is opposed by another set which extends the forearm. Now, if one set of muscles is paralyzed and not the other, it can be readily understood how the pull of the

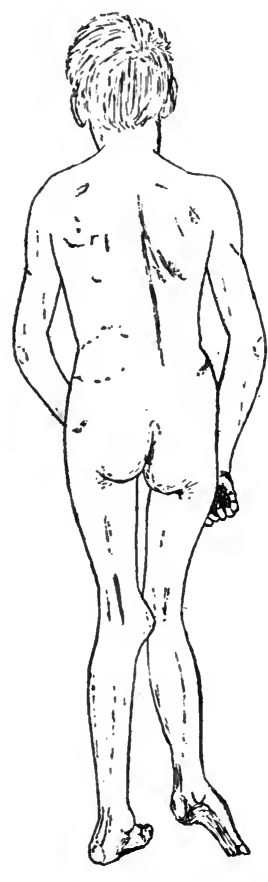

Fig. 20

Infantile Paralysis. (Anterior poliomyelitis of right leg) (Bradford and Lovett). active muscles would cause contraction and deformity. Sometimes horrible deformities may result and the child be unable to walk at all, or at best walk like an animal, on all fours.

There is always marked atrophy of the paralyzed part (Fig. 20), and it is cold and lifeless to the touch.

Treatment.- The treatment of the acute stage is not the province of orthopedic surgery. Orthopedic surgery is concerned only with the resulting deformities. Electricity, massage, muscle training, and the use of braces are all important aids in combating deformity and in building up weakened muscles. After deformities have occurred, surgical measures, such as forcible manipulation, tendon cutting (tenotomy), muscle transference, the insertion of artificial silk ligaments, nerve anastomoses, etc., are required. $\Lambda$ fter the correction of the deformity the correction must be held by the use of braces, muscle training, etc. The treatment is usually long and re- 
quires much patience, but it is oftentimes surprising how much can be done to relieve what would otherwise. be a most distressing condition.

\section{BIRTH PALSY}

Birth Palsy, Spastic Paralysis or Little's Disease, as it is variously known, is a disease characterized by

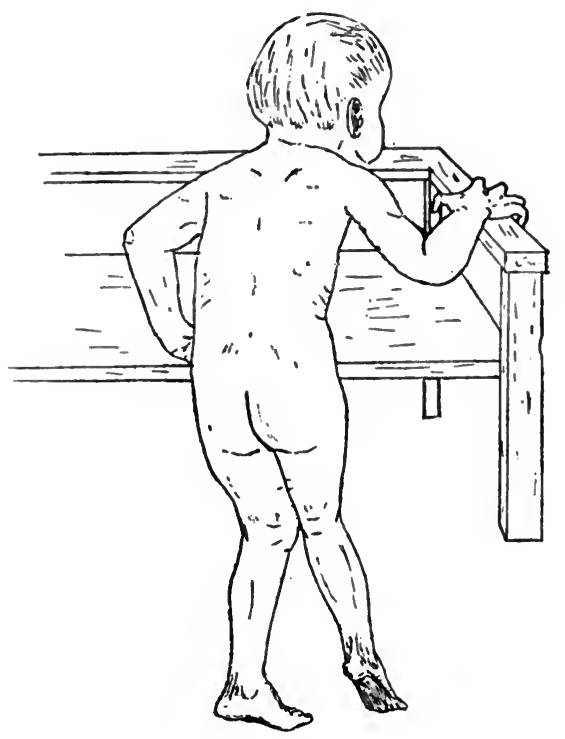

Fig. 21.

Spastic Paralysis (Littie's disease). Characteristic attitude (Whitman).

muscle weakness and inco-ordination by muscle stiffness (spasm) and loss of control. 
Causes.-The cause of the disease is supposed to be an injury to the higher nerve centers. It is often due to an injury to the brain of the child in cases of severe labor where forceps are used; hence the term birth palsy.

Symptoms.-The disease is usually ushered in with convulsions followed by paralysis of the spastic type. This is a type of paralysis different from infantile paralysis. In the latter disease the affected limbs are limp and "hang dead," in birth palsy the affected limbs are held stiffly, and are spastic (Fig. 21). The muscles are not actually paralyzed; they can contract, but there is a loss of co-ordination, a loss of control over them. The intellect is very apt to be affected in cases of spastic paralysis, the child being more or less feeble minded. There are also present peculiar movements of the hands and arms known as athetoid movements. Atrophy of the affected limbs is not so marked as in infantile paralysis.

The course of the disease is progressively deforming, and contractures occur as in infantile paralysis.

Treatment.-In the treatment of the later stages, after deformity has occurred, practically the same principles apply as in the treatment of infantile paralysis.

\section{TUBERCULOSIS}

Tuberculosis is an infectious disease, which, when it affects the bones and joints, causes destruction of tissues with deformity. The cause of the disease is the tubercle bacillus. 
Symptoms.-The symptoms vary with the location of the disease, but there are certain general symptoms that are always present and common to any localizing focus. These are:

Pain.

Tenderness.

Stiffness (muscle spasm).

Deformity.

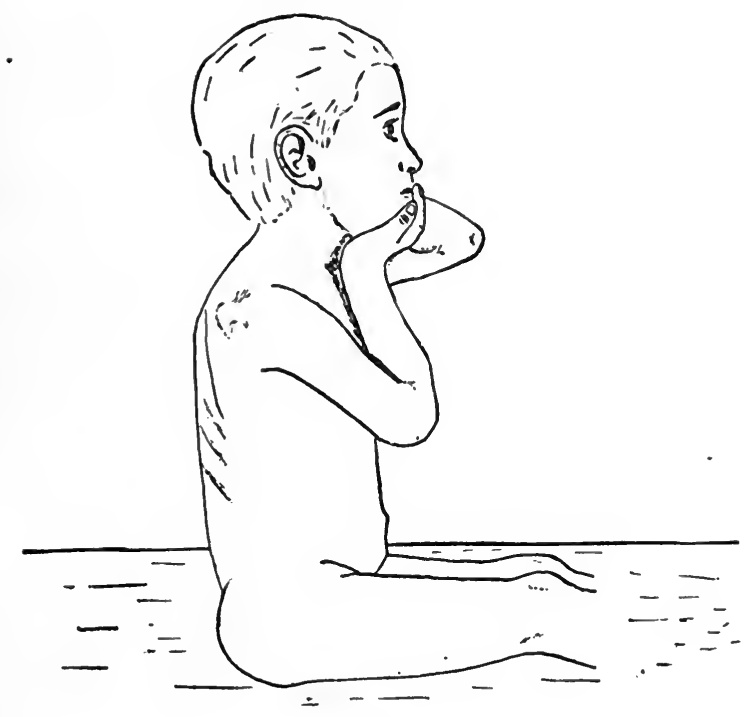

Fig. 22.

Tuberculosis of the cervical spine (Pott's disease). Characteristic attitude to avoid jarring of the diseased vertebra (After Whitman).

Also there is a "falling off" in the general health of the patient. The patient tires easily, is irritable, and 3 
in children there is a restlessness during sleep and "night eries." The night eries are due to the fact that in sleep the muscles, which by their contraction during the day kept the diseased parts protected, are now relaxed and any movement causes pain.

The symptoms of the disease when localized in the most usual situations are as follows:

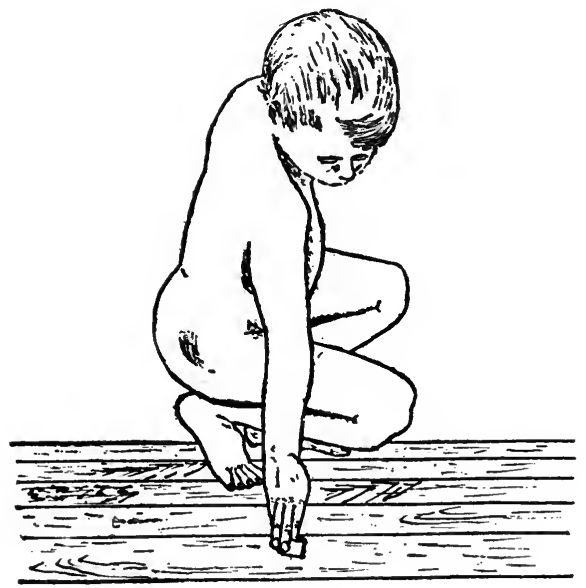

Fig. 23.

Tuberculosis of the dorsal spine (Pott's disease). Characteristic attitude. Showing rigidity of the spine (After Whitman).

In the spine (Pott's Disease):

Pain.-The patient complains of pain in the back or in the abdomen. Whenever a child complains of continued pain in the abdomen, for which no other cause can be found, the spine should always be examined for beginning tuberculosis. 
Tenderness.-The spine is sensitive to jarring of any kind (Fig. 22). Running or rough riding may be painful.

Stiffness.-On account of the above the spine is held stiffly by muscle spasm and is not bent. Thus in

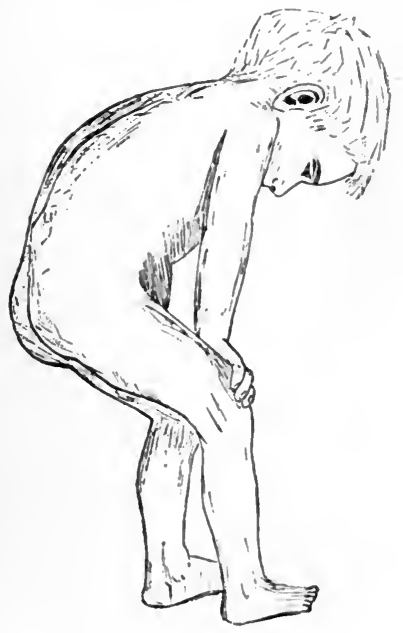

Fig. 24.

Tuberculosis of the dorsal spine (Pott's disease). Characteristic attitude to avoid jarring of the spine.

In the hip: picking up objects from the floor the back is held rigid and all bending is made at the hips and knees (Figs. $23,24)$.

Deformity.-In the later stages of tuberculosis of the spine a knuckle of bone appears on the back over the seat of the trouble. This is due to the diseased bone crumpling up and forcing the spinous processes of the vertebræ backward (Figs. $25,26)$.

Pain.-The patient complains of pain in the hip or in the knee. When a child complains of pain in the knee, and no cause is evident, the hip should be examined for beginning tuberculosis.

Tenderness.- The hip is sensitive to jarring and motions of all kinds. 
Stiffness.-The stiffness of muscles around the hip (muscle spasm), causes the hip to be held more or less rigid. It is usually held in such a position that the leg on that side seems longer or shorter

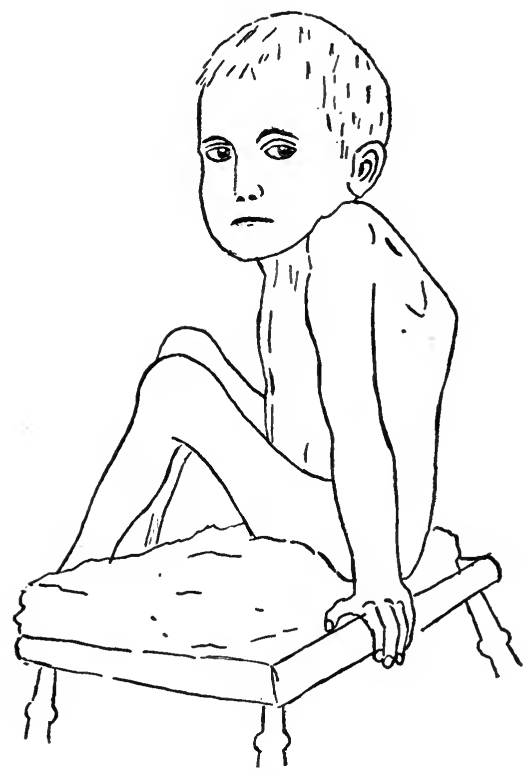

Fig. 25.

Deformity (kyphosis) in tuberculosis of the spine (After Whitman).

than the opposite one, although the actual length of the two legs may be the same Fig. 27). The result is that the child walks with a limp.

Deformity.-In the later stages, due to contractions and bony destruction, the leg may become deformed and flexed on the thigh (Fig. 28). 
In the knee and other joints, (Fig. 29) the symptoms are:
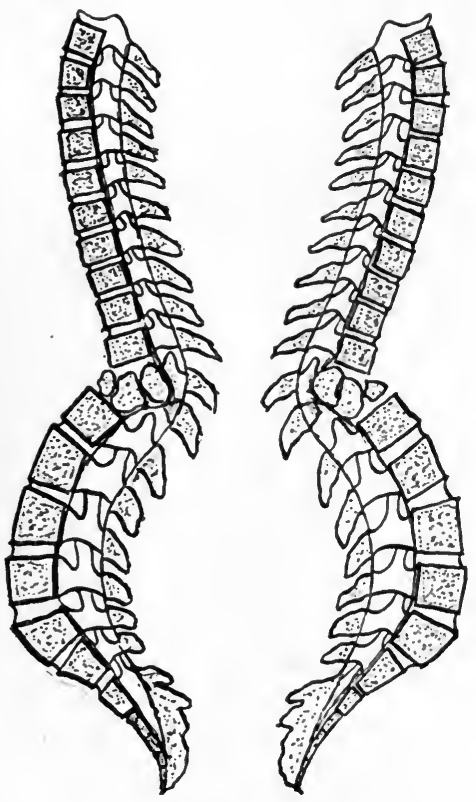

Fig. 26 .

Sagittal section of kyphosis in tuberculosis of the spine (Pott's disease).

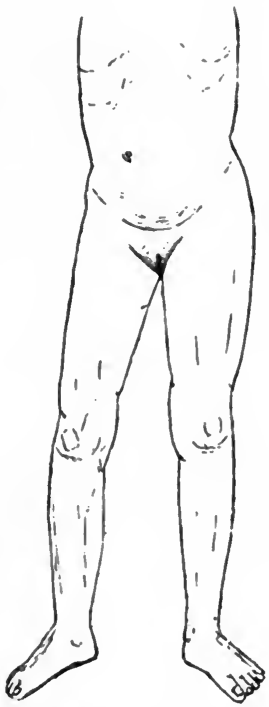

Fig. 27.

Tuberculosts of the hip. Characteristic attitude in the eariy stage of tuberculosis of the right hip. The pelvis is tilted in such a way that the right leg appears to be longer than the left.

Pain.

Tenderness.

Stiffness (muscle spasm).

Deformity swellings and contractions. 


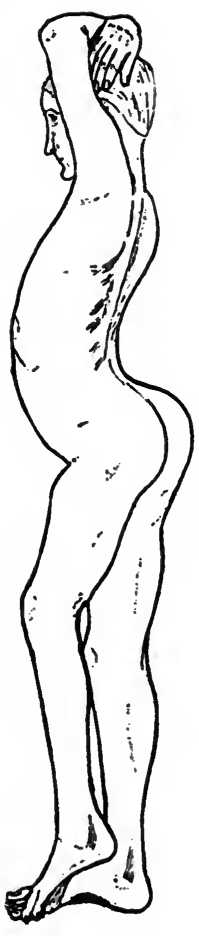

Fig. 28.

Tuberculosis of the hip. Characteristic attitude in a d v.a n c e d stage of tuberculosis of $t h$ e left hip. The left leg is shortened and atrophied, and the thigh is flexed onto the abdomen so that in order to bring the foot to the ground the spine has to bend forward (lordosis) (After Whitman).
The course of tuberculous disease in all cases, unless properly treated, is progressively worse, with the production of very severe deformities. The deformities are due to two causes: first, contraction and second, the actual destruction of tissue. The later stages of tuberculous disease are frequently complicated by abscess formation, the usual result being that the abscess ruptures and forms a persistent discharging sinus or "running sore."

In recognizing tuberculosis any pains in the bones or joints of a child should not be neglected or attributed to "growing pains." The common story in many cases of tuberculosis is something like this: The mother asks: "Do you think Willie walks with a limp? He does not look well to me; he seems all right in the morning but he tires so easily and sometimes toward night it seems to me that he walks with a limp. Sometimes he says his hip hurts him and sometimes he complains of his knee. He is restless at night and wakes up crying and says his knee hurts. I have looked at his knee and it looks all right. His father thinks it is nothing but rheumatism or growing pains. I have thought of tak- 
ing him to the doctor but maybe that would be foolish. Do you think it is growing pains?" This would be the

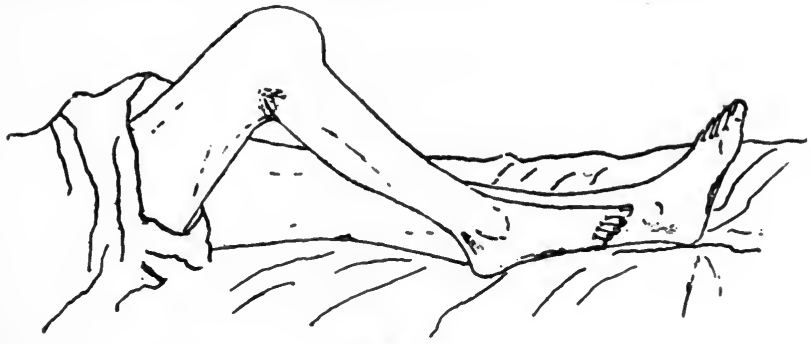

Fig. 29.

'Tubercuiosis of the knee. Characteristic appearance. (Bradford and Lovet $t$ ).

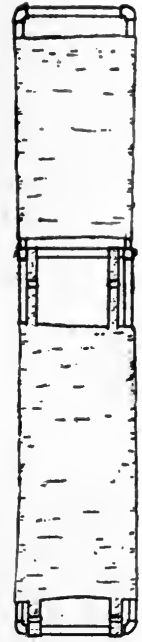

Fig. 30.

Bradford frame. A gas pipe frame covered with canvas. time, if ever, for a trained nurse to show her knowledge. Probably the boy has beginning tuberculosis of the hip, and, if a diagnosis can be made and proper treatment started, the trouble may be checked before serious damage has taken place.

Treatment.-The three great essentials in the treatment of tuberculosis are rest, fresh air and good food, but nature must cure the disease. Rest is obtained for children by placing them on a gas pipe frame covered with eanvass (Bradford frame, Whitman frame, etc.) (Figs. 30, $31,32)$. The use of plaster-of-Paris casts and braces is another way of employing rest treatment, since they hold the diseased parts and prevent motion (Figs. 33, 34, 35, 36). When the disease is clearly localized in a bone or 


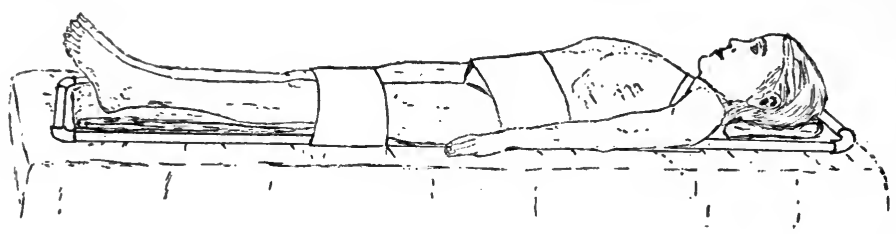

Fig. 31.

Patient on a Bradford frame.

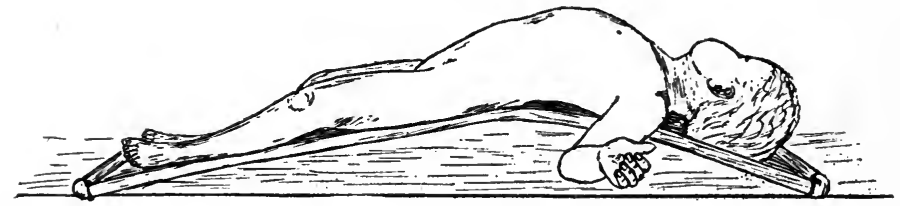

Fig. 32.

Patient on a Whitman frame.

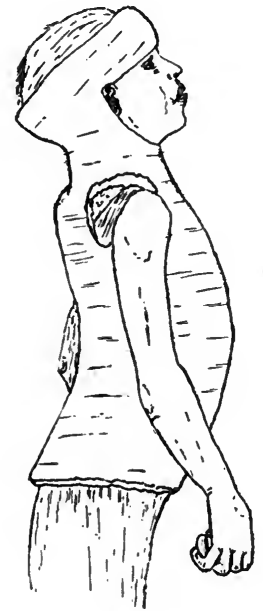

Fig. 33.

Plast er-of-Paris cast applied for tuberculosis of $\mathrm{the}$ spine.

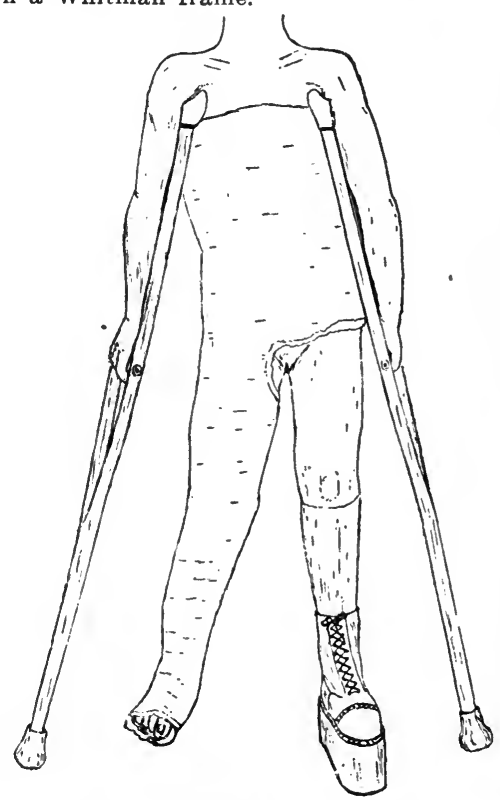

Fig. 34.

Plaster-of-Paris cast applied for tuberculosis of the hip. 
joint it may be possible to operate and remove the affected area. After the disease has healed and left deformities they may be corrected or improved by operative treatment. The treatment of tuberculosis is usually a slow and tedious process, and must be persisted in to effect a cure.

\section{CHRONIC DEFORMING ARTHRITIS}

The name describes the disease; a chronic disease of the joints deforming them. There are two forms of chronic deforming arthritis, commonly known as senile osteo-arthritis and rhemmatoid arthritis.

Senile osteo-arthritis is very common; probably there are very few people over sixty years of age who do not show evidence of the disease in more or less degree. The most common situation of the disease is in the fingers, where it manifests itself in knobby swellings about the joints. These nodules are small bony outgrowths and are known as IIeberden's nodes. They are slightly painful and tender, and cause stiffness of the fingers. No constitutional symptoms eharacterize the disease.

The next most common situation of the discase is in the knee joints. The attention of the patient is usually first called to the trouble by a grating sound on moving the knee. Pain and stiffness in the knee may become very pronounced and the patient suffers severely. The disease may attack the hip, the spine, or in fact any joint of the body. 
The treatment of senile osteo-arthritis is very unsatisfactory.

Rheumatoid Arthritis attacks younger subjects, and oftentimes an infection seems to be at the bottom of the

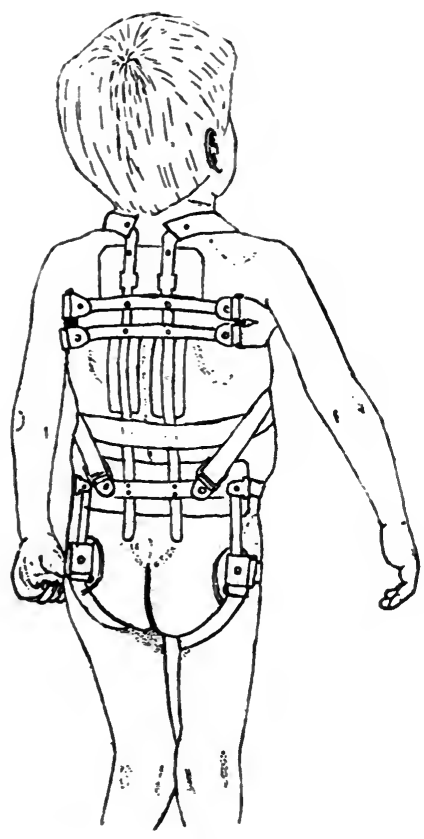

Fig. 35.

Rear view of brace applied for tuberculosis of the spine (Bradford and Lovett).

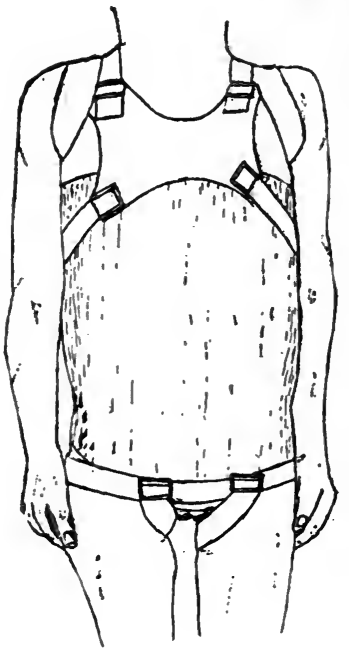

Fig. 36 .

Front view of brace applied for tuberculosis of the spine (Bradford and Lovett).

trouble. For example, it may follow a suppurative tonsillitis, an old ulcerated tooth, etc.

Symptoms.-Unlike senile osteo-arthritis this form of 
chronic arthritis is accompanied by constitutional symptoms. The patient feels and looks ill, there may be fever and chills. The joints become swollen, stiff and painful; the swelling is fusiform in shape and the skin over it is waxy looking. The affected part perspires profusely with a cold perspiration. Deformities of the various joints take place, due to contractures, and the patient may become permanently bedridden.

Treatment.-The treatment of rheumatoid arthritis is to remove the suppurating focus, if such can be found (diseased tonsil, ulcerated tooth, etc.). In cases where the disease has become quiescent the resulting deformities may be helped by operation.

Other deforming diseases such as gout, osteitis deformans, multiple exostoses, etc., are too technical or too common to be more than mentioned. 


\section{CHAPTER III \\ REGIONAL DEFORMITIES}

The Neck

\section{ACQUIRED WRY-NECK}

Congenital wry-neck or torticollis was discussed in the first chapter, but there are also acquired forms of this deformity. The most common form of Acquired Wry-Neck is that caused by "catching cold" in the neck muscles, "stiff neck" as it is commonly called. Acquired wry-neck is also associated with traumatism, rheumatism, rickets, tuberculosis, etc. The appearance of the acquired deformity may be the same as that of the congenital type (Fig. 12), but the history of the onset will serve to differentiate the two. The treatment of acquired wry-neck is primarily the treatment of the condition cansing it.

In the wry-neck associated with "catching cold" the only thing required is heat in the form of hot compresses. In rachitic wry-neck the general rachitic condition may be treated, and in the wry-neck associated with tuberculosis the diseased cervical vertebra must be supported.

\section{CERVICAL RIB}

An extra rib may be present in the neck, causing a deformity known as Cervical Rib. The extra rib may 
be present on one or both sides, and is placed immediately above what would otherwise be the first rib (Fig. 37 ); it may press upon a nerve trunk and cause symptoms of pain and paralysis of the arm. The

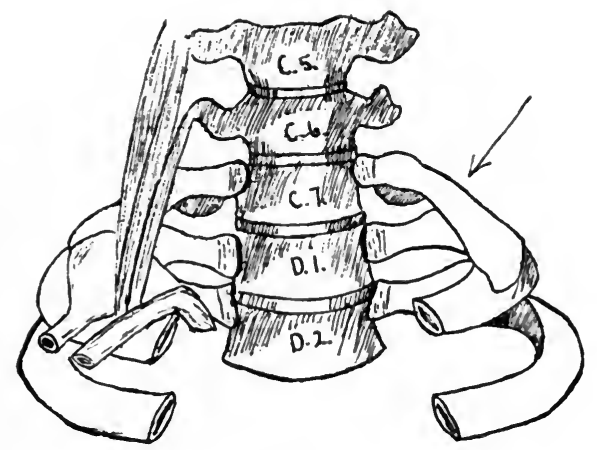

Fig. 37.

Cervical rib. The arrow points to the cervical rib.

treatment of such a condition is surgical removal of the extra rib.

\section{The Chest}

The important orthopedic deformities of the chest are four in number and are: rachitic rosary, Harrison's groove, pigeon breast and funnel chest. Rachitic rosary and Harrison's groove are associated with rickets. 


\section{RACHITIC ROSARY}

The rachitic rosary (Fig. 16) is a beading of the ribs at their junction with the sternal cartilages. It is due to the same rachitic process which causes the wrists and ankles to enlarge.

\section{HARRISON'S GROOVE}

Harrison's groove (Fig. 38) is a longitudinal furrow across the chest at the level of the attachment of

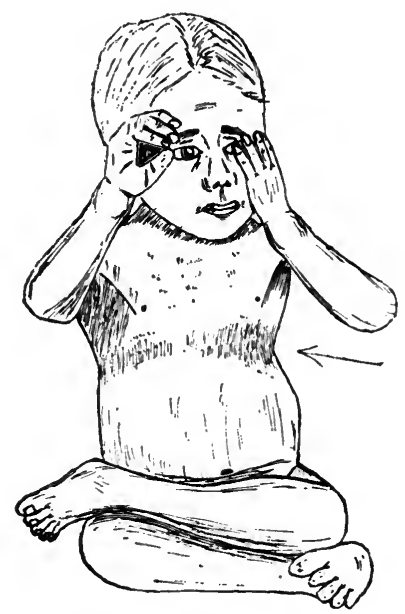

Fig. 38 .

Harrison's Groove. The arrow points to the groove.

the diaphragm. It is supposed that the pull of the diaphragm on the softened ribs causes them to bend inward. 


\section{PIGEON BREAST AND FUNNEL CHEST}

Pigeon Breast and Funnel Chest (Fig. 39) are deformities more commonly associated with mouth breathing in children; the mouth breathing being due to adenoids or enlarged tonsils. The fact that such deformities of the chest develop in mouth breathers is
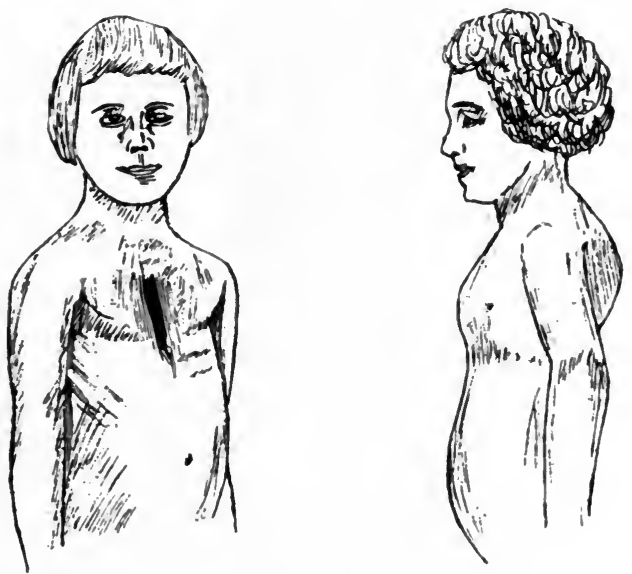

Fig. 39.

Plgeon breast and funnel chest. The child on the right has pigeon breast anc the child on the left has funnel chest.

one of the several reasons why adenoids and enlarged tonsils should be diagnosed early and removed.

\section{The Spine}

The common deformities of the spine are: kyphosis, round back; lordosis, hollow back; scoliosis, lateral curvature. 


\section{KYPHOSIS}

A simple Kyphosis is an exaggeration of the slouching attitude-the lazy attitude-"round shoulders" (Figs. 40,41). Children at the most rapidly growing

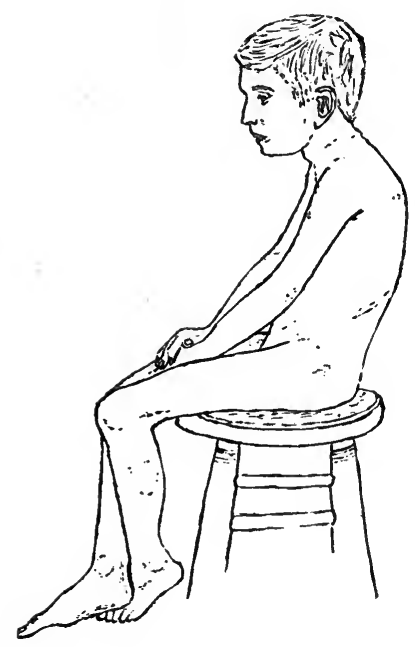

Fig. 40.

Round shoulders (kyphosis).

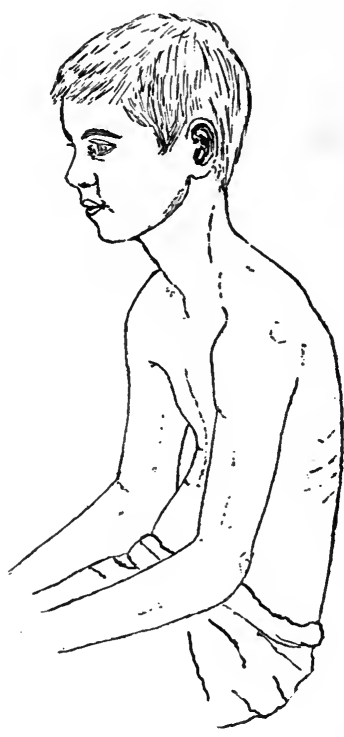

Fig. 41.

Round shoulders (kyphosis).

age (eight to fourteen ycars) almost always have to be told to stand straight; if they do not stand straight the round shoulders or kyphosis may become a fixed deformity (Fig. 42). In tuberculosis of the spine the deformity takes the form of an angular kyphosis, 
the bodies of the vertebra crush down together and the spinous processes are pushed backward, forming the characteristic "hunch-back" (Figs. 25, 26).

Kyphosis, unless checked, is a progressive deformity.

The treatment of simple kyphosis is to instruct the patient in systematic exercises to strengthen the muscles of the back and to cultivate an erect posture. The tuberculous kyphosis requires special treatment by plaster casts, forcible correction or operation.

\section{LORDOSIS}

Lordosis, or bending forward of the spine, is, as a rule, a secondary deformity. For example, in double congenital dislocation of the hip the heads of the femurs are displaced backward, and to compensate for this and allow f red ed shoulders, the body to maintain the erect atti- pensatory lordosis. tude, the spine must bend forward in the lumbar region (Fig. 43). Lordosis is also present as a deformity secondary to kyphosis. If a marked bending backward of the spine is present there must also be present a forward bending to compensate and allow the erect attitude to be maintained (Fig. 42). The deformity is unsightly, and on account of the peculiar position of the abdomen is apt to cause enteroptosis (sagging of the abdominal organs). 
The treatment of lordosis is attention to the original cause of the deformity.

\section{SCOLIOSIS}

Scoliosis, or lateral curvature of the spine, is one of the most distressing deformities of orthopedic surgery. It usually first shows itself about the age

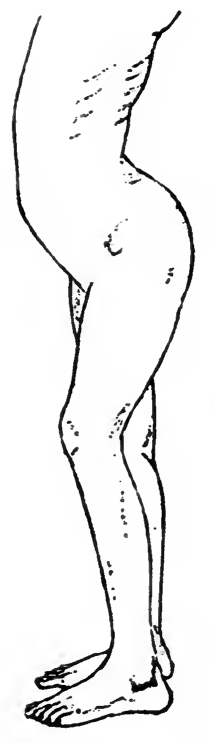

Fig. 43. of puberty and is more common in girls than in boys.

The cause of lateral curvature of the spine is not thoroughly understood; general weakness or rachitic tendency seem to be the cause in some cases, at other times the deformity appears to develop without any recognized cause. Rapid growth, associated with the age of puberty and the physical strain of school life, aggravate the condition, and sometimes would seem to be the principal etiological factor.

The symptoms are for the most part objective, and frequently the deformity is well advanced before it is noticed. The child may have been listless and lazy Lordosis sec- acting, always standing on one foot and
ondary to conondary to congenital disloca-
tion of the hip. sitting in a slouching attitude; then one day someone notices that one shoulder of the child is higher than the other or one hip or one shoulder blade is more prominent than the other (Figs. 
$44,45)$, and on closer examination the typical S-shaped curve of the spine is found. A dressmaker is often the first to discover the deformity in a girl, it being found necessary to pad a shoulder or hip to make the dress fit perfectly.

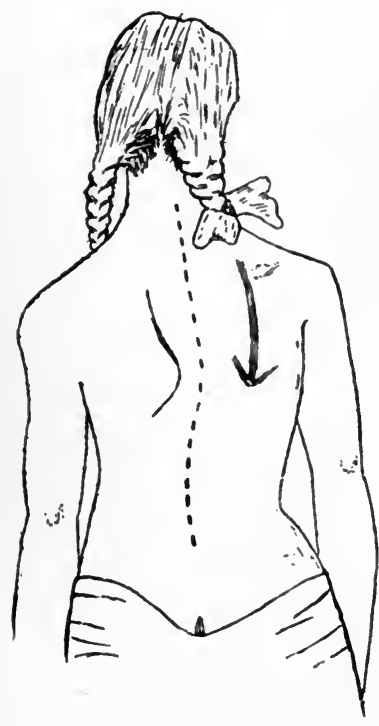

Fig. 44.

Early stage of lateral curvature of the spine (scoliosis). High shoulder and prominent shoulder blade, right side.

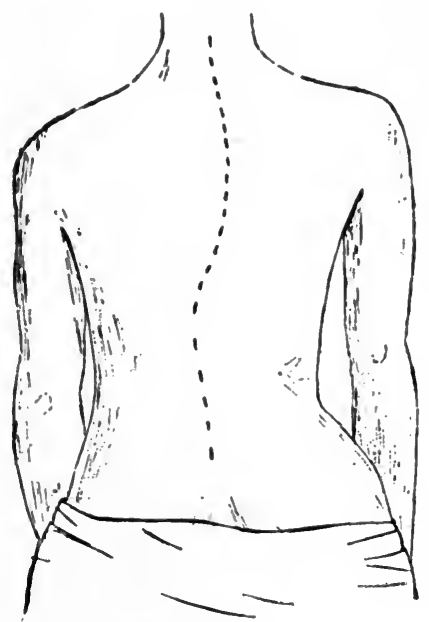

Fig. 45.

Early stage of lateral curvature of the spine (scoliosis). Prominent hip, right.

The tendency of the curvature is to progress rapidly. The S-shaped deformity becomes very marked, and the distortion of the spine and ribs is so great that the heart and lungs are pressed upon, affecting the general 
health (Fig. 46). The spinal nerve trunks may be pressed upon and irritated and cause severe pain.

In the early stages the spine takes on the S-shaped deformity, seemingly due to muscular weakness, but

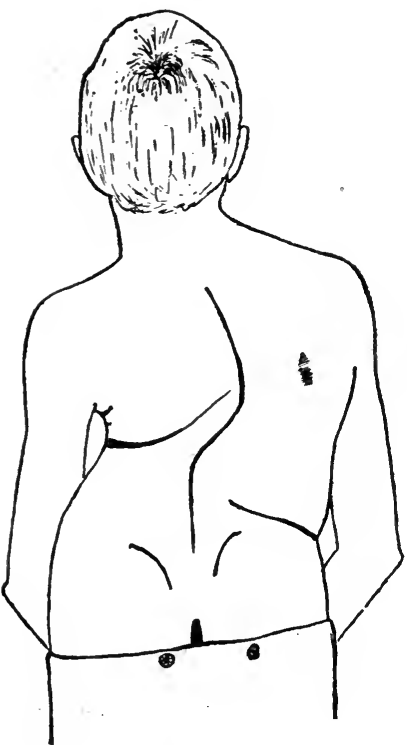

Fig. 46.

Advanced stage of lateral curvature of the spine (scoliosis).

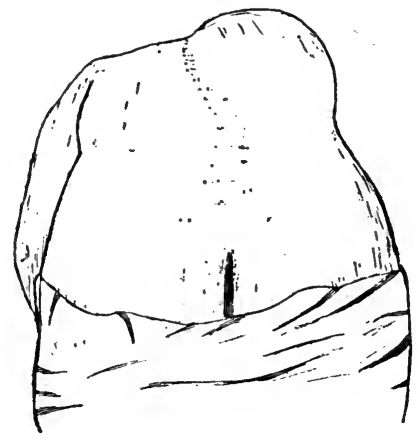

Fig. 47.

Curvature of the spine. of the spine and ribs.

can be straightened by voluntary effort of the child. In an untreated case the child soon tires of the voluntary effort to keep erect and slouches down again into the deformed position. As time goes on the voluntary correction becomes impossible, and the curvature becomes fixed or "structural" as it is called. 
Associated with structural curvature of the spine there is rotation of the spine and ribs, which is best shown by having the patient bend forward at the waist, whereupon the rotated ribs become very prominent (Fig. 47).

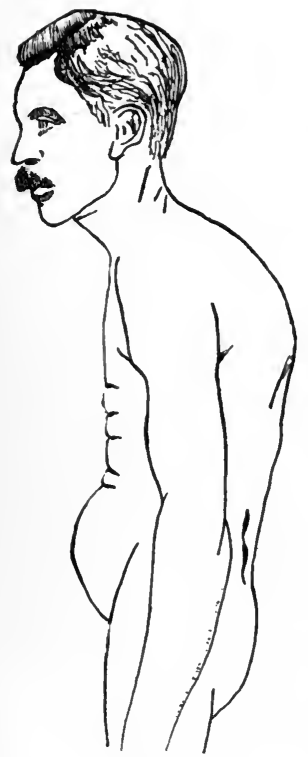

Fig. 48.

Spondylitis deformans. Characteristic attitude (After Whitman).

Treatment.-Treatment in the early stage consists of rest, tonics, good food, fresh air and trained muscular exercises to strengthen the weakened muscles. At a later stage correction of the deformity by plaster casts may be necessary, and in still later stages, when actual bony change has taken place, no cure is possible.

The importance of recognizing the condition at an early stage can readily be seen. A child who is listless, tires easily, persistently stands on one foot or sits in a slouching attitude should always be suspected of having a beginning curvature of the spine and should be thoroughly examined accordingly.

\section{SPONDYLITIS DEFORMANS}

Spondylitis deformans is the spinal form of senile osteo-arthritis. The spine becomes stiff and rigid and 
is either held perfectly straight, "Poker-back," or as a rounded kyphosis (Fig. 48).

Treatment of the condition is very unsatisfactory.

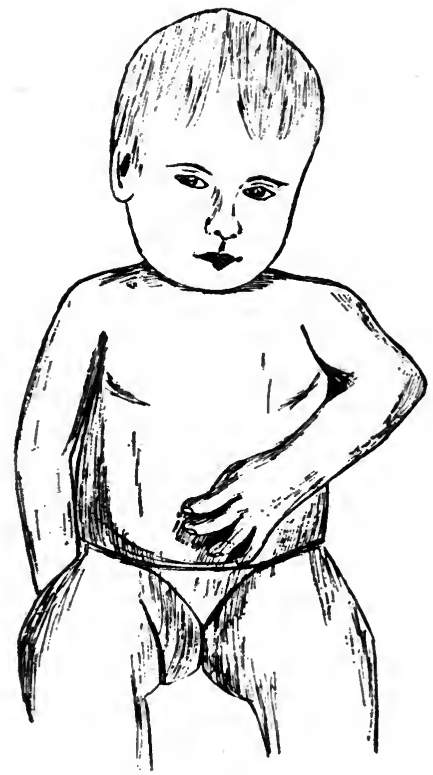

Fig. 49.

Congenital dislocation of the left shoulder. Characteristic attitude.

\section{The Shoulder}

CONGENITAL DISLOCATION OF THE SHOULDER

Congenital Dislocation of the Shoulder is not a common deformity; but, when it is present, it may be 
mistaken for obstetrical paralysis. The position in which the affected arm is held is very characteristic (Fig. 49).

\section{OBSTETRICAL PARALYSIS}

Obstetrical Paralysis of the shoulder is an acquired deformity caused by an injury to the nerve trunks

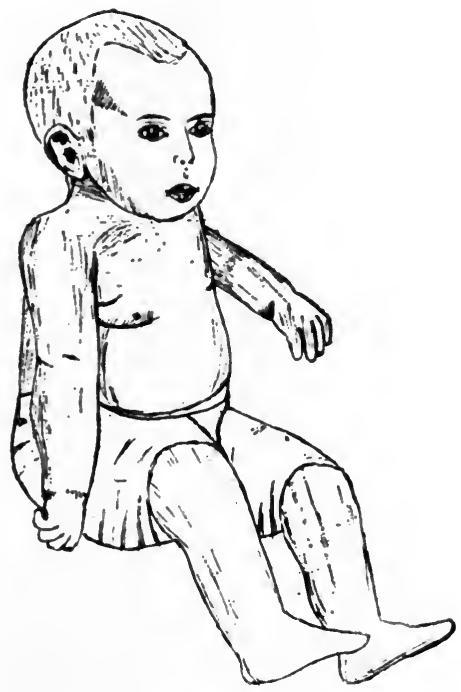

Fig. 50.

Obstetrical paralysis of the right shoulder. Characteristic attitude (After Whitman).

supplying the shoulder and arm muscles at the time the child is born. The injury is supposed to be a rupture or tearing of the nerve trunks, and is fairly 
common in cases of difficult labor where the child has . to be pulled upon in delivery.

The condition shows itself shortly after birth when it is seen that the child cannot use one arm and it hangs limp and "dead" as in infantile paralysis (Fig. 50).

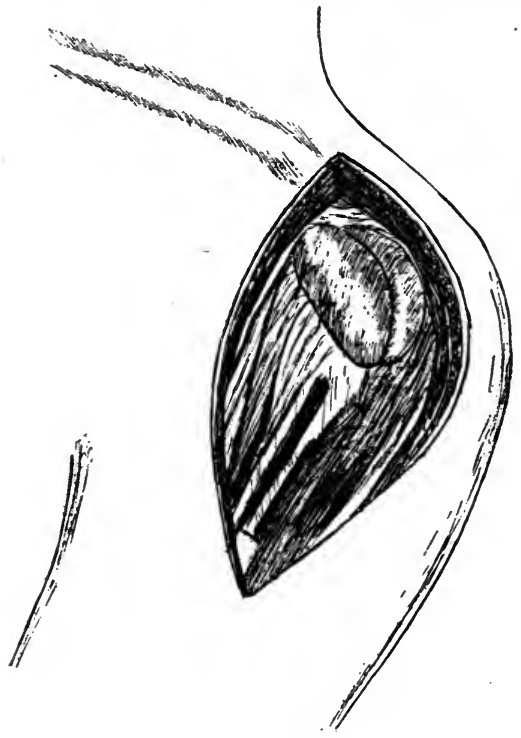

Fig. 51.

Subdeltoid bursitis. The sac of the bursa underneath the deltoid muscle.

The paralysis may be slight or extensive, depending upon the extent of the injury to the nerve trunks.

Treatment consists in supporting the affected shoulder and arm in a bandage, gentle massage, and trying to make the baby use the arm. Operative measures such as nerve repair, nerve anastomosis, muscle 
transplantation, insertion of artificial silk tendons, ete., have been used in some cases.

\section{BURSITIS}

One of the most common acquired deformities, or rather disabilities, of the shoulder is what is known as Sub-Deltoid Bursitis. Between the deltoid muscle (the muscle which lies over the point of the shoulder and raises the arm from the side) and the bone there is a small sac called a bursa; it serves to protect the muscle from the bone (Fig. 51). Sometimes due to injury or other causes the sac becomes inflamed, causing a bursitis. The shoulder becomes stiff and painful and very annoying. The treatment of the condition is rest and heat to the part, but sometimes it may become necessary to aspirate or dissect out the bursa before relief is obtained.

\section{The Elbow}

\section{TENNIS ELBOW}

There is an acquired disability of the elbow known as, "Tennis Elbow." It is supposed to be due to a periostitis or to an arthritis caused by playing temis or other similar exercise. The essential treatment is rest to the joint.

\section{The Wrist and Hand}

The wrist and hand may be congenitally deformed in various ways. The deformities are very evident when present, and need no special discussion. 


\section{VOLKMANN'S ISCHEMIC PARALYSIS}

An acquired deformity of the wrist and hand, now rarely seen since its cause has been discovered, is Volkmann's Ischemic Paralysis. This deformity is caused by putting on splints too tightly or not padding them sufficiently. The blood supply is interfered with and the

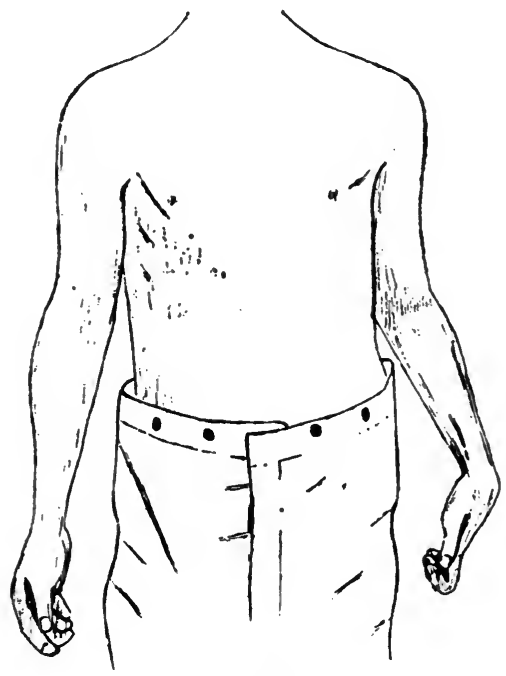

Fig. 52.

Volkmann's ischemic paralysis of left arm and hand.

nerves are affected, causing a contracture to occur (Fig. 52). A trained nurse, whenever called upon to apply an emergency splint, should bear in mind the danger of this deformity, pad the splint sufficiently, and not apply it too tightly. 
The treatment of the deformity when it is once established is very unsatisfactory.

\section{GANGLION}

Another acquired deformity of the wrist and a very common one is what is known as Ganglion; sometimes called "weeping sinew." A ganglion is a slightly painful globular swelling of the wrist, usually posterior, associated with more or less weakness of the joint (Fig.

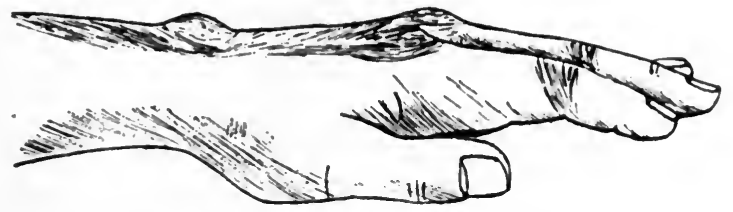

Fig. 53.

Ganglion of the wrist.

53). It is a hernia of a tendon sheath or of the synovial membrane of the wrist joint and the sac is filled with a clear gelatinous material. Sometimes the tumor can be ruptured subcutaneously and made to disappear; in other cases it is necessary to operate and remove the sac.

\section{The Fingers}

The congenital deformities of the fingers are webfingers, missing fingers, extra fingers, etc. 


\section{DUPUYTREN'S CONTRACTURE}

Dupuytren's Contracture is an acquired deformity supposedly caused by an injury to the palmar fascia, causing it to contract. As the fascia contracts it flexes

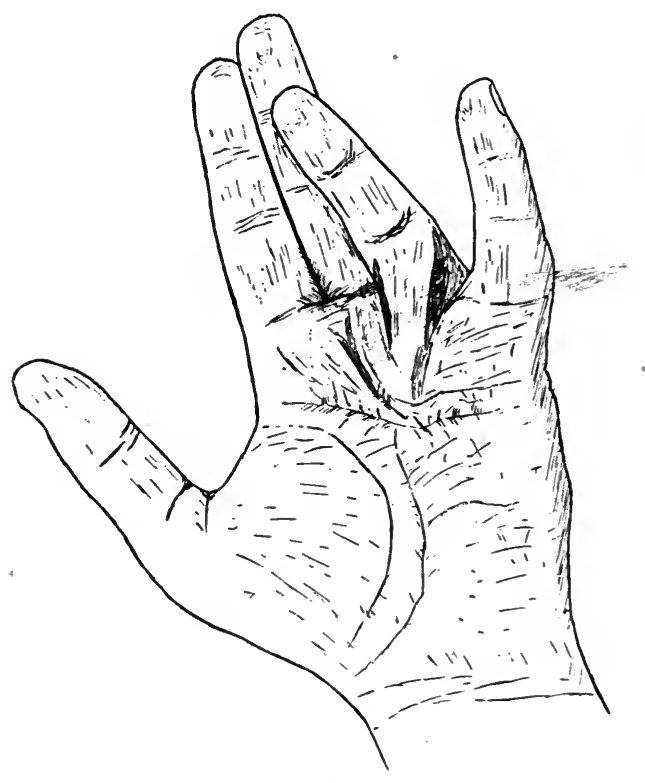

Fig. 54.

Dupuytren's contracture.

first one finger and then another down into the palm of the hand. The ring finger is the one usually first affected (Fig. 54).

The treatment of the condition is to dissect out and remove the palmar fascia. 


\section{MALLET FINGER}

Mallet Finger is an acquired deformity caused by an injury to the extensor tendon of the finger. As a consequence, the end phalanx drops forward and gives the appearance of a mallet (Fig. 55).

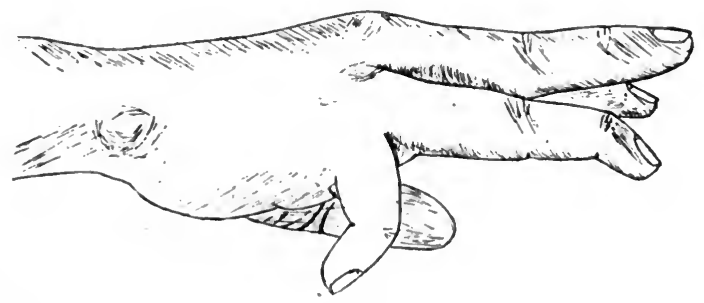

Fig. 55.

Mallet finger (fourth finger).

Operative treatment is necessary to restore the injured tendon.

\section{TRIGGER FINGER}

Trigger Finger is an acquired disability in which, in extension or flexion, the movement is arrested for a moment and then is continued with a distinct and sometimes audible snap. It is due to an obstruction of the tendon in its sheath. The treatment is to remove the cause of the obstruction. 


\title{
CHAPTER IV \\ REGIONAL DEFORMITIES-Continued
}

\author{
The Pelvis
}

STRAIN OF THE SACRO-ILIAC JOINTS

The most common orthopedic disability associated with the pelvis is strain of the sacro-iliac joints.

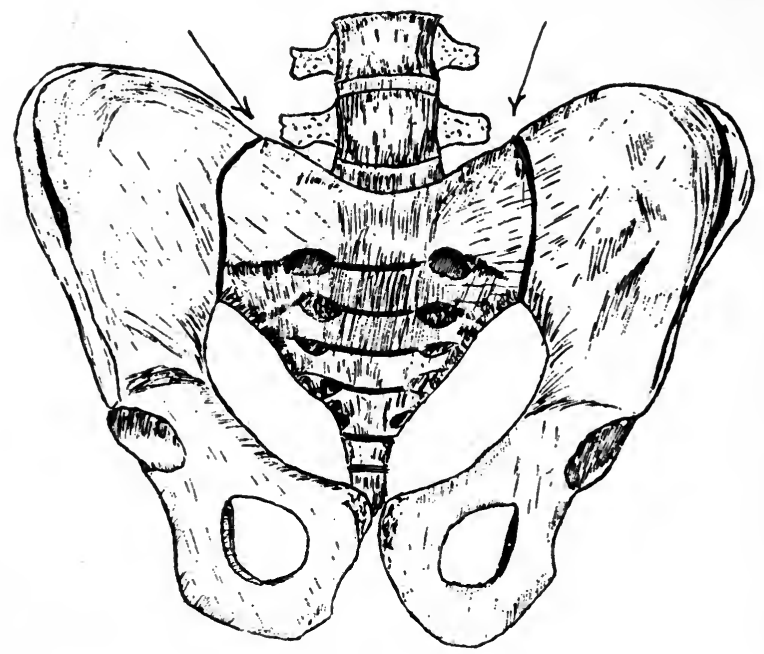

Fig. 56 .

The pelvis showing the sacro-iliac joints. The arrows point to the sacro-iliac joints.

These joints are situated low down in the back at the junction of the sacrum and iliac bones (Fig. 56), and 
are subject to strain in heavy lifting, accidents which wrench the back, etc. The symptoms of strain are pain and stiffness referred to the region of the joints. The pain may be acute in character and radiate down the back of the thigh, resembling sciatica, or it may radiate in front to the inguinal region. At other times there may be simply a constant dull pain in the lower back.

The treatment is rest, support to the joint and in very severe cases it is sometimes thought advisable to operate and ankylose the joints.

\section{The Hip}

Congenital dislocation of the hip and tuberculosis of the hip, the two most important orthopedic deformities of that region, have already been discussed.

\section{The Knee}

Tuberculosis of the knee and chronic arthritis of the knee have already been discussed under the heading of "Acquired Deformities Caused by Disease."

There are three important structural deformities of the knee known as:

Genu valgum (knock-knee).

Genu varum (bow-legs).

Genu recurvatum (backward bending). 


\section{GENU VALGUM AND GENU VARUM}

Genu Valgum and Genu Varum (Figs. 57, 58) are deformities usually associated with rickets, and are objectionable principally on account of their appearance. In mild cases the deformity may be outgrown,

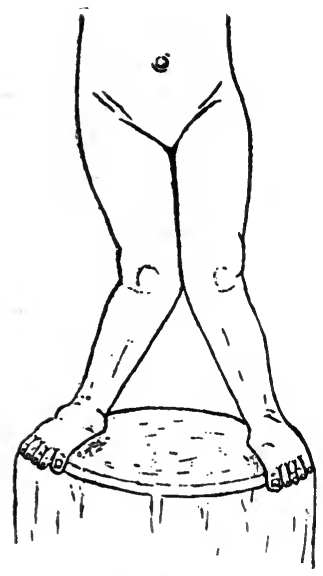

Fig. 57.

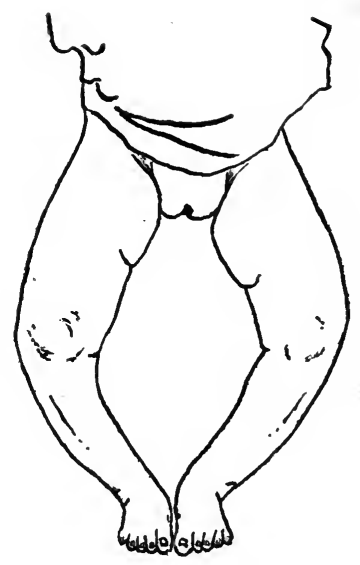

Fig. 58.

Genu valgum (knock-knee). Genu varum (bow-legs).

otherwise the crooked bones have to be broken, straightened and held in position by a plaster cast until union has taken place. 


\section{GENU RECURVATUM}

Genu Recurvatum (Fig. 59) is a deformity which more commonly follows paralytic conditions. Braces can be used to hold the leg straight.

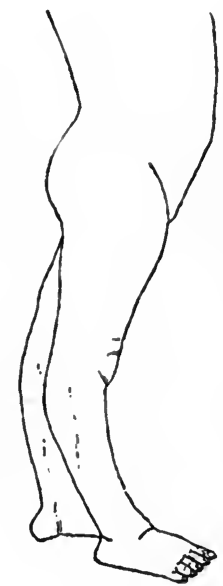

Fig. 59.

Genu recurvatum.

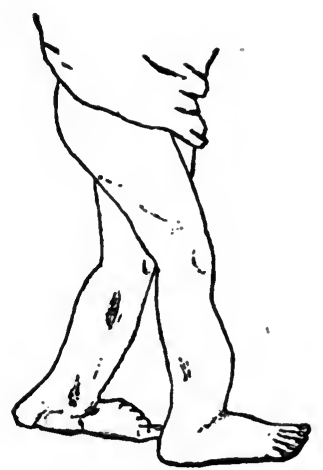

Fig. 60.

Anterior bowing of the legs (After Whitman).

\section{ANTERIOR BOWING OF THE LEGS}

An Anterior Bowing of the Legs may occur as a congenital affection or as the result of rickets (Fig. $60)$. This particular deformity of the legs is rarely "outgrown" and correction has to be made by operation. A wedge-shaped piece of bone is removed and the leg straightened. 


\section{HOUSEMAID'S KNEE}

Housemaid's Knee, so-called because of its frequent occurrence in housemaids who kneel when scrubbing, is the common name for pre-patellar bursitis. The prepatellar bursa is situated just in front of the patella (the knee-cap), and when injured or irritated may become inflamed, swollen and very tender (Fig. 61).

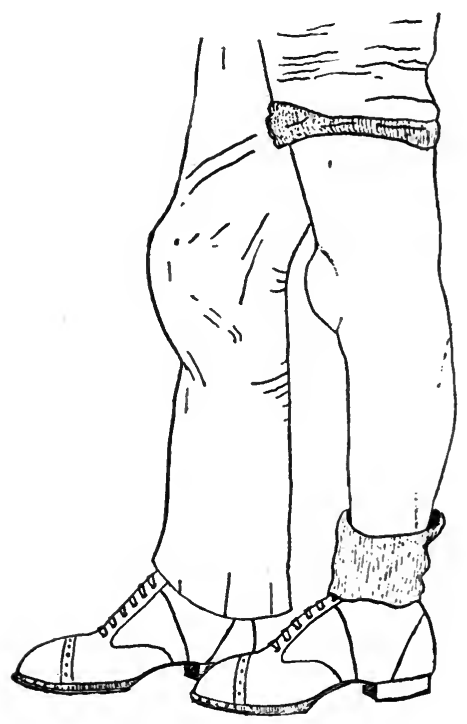

Fig. 61.

Housemaid's knee (pre-patrllar bursitis). Left knee (Bradford and Lovett).

The treatment in mild cases is to bandage the part tightly. Sometimes it is best to aspirate the contents of the inflamed bursa and then apply a firm bandage. 
At other times, in order to effect a cure, it is necessary to operate and remove the bursa.

\section{FLOATING BODIES}

Floating Bodies or Loose Bodies in the knee joint are at times the cause of very severe disability. The floating bodies may be small pieces of detached bone following an injury; they may be calcified portions of detached synovial membrane, calcified blood clot, etc. They move around in the joint until caught between the bones, when they cause a sudden sharp pain and locking of the joint; this is usually followed by swelling and an acute inflammation. The same condition may be present in other joints, especially the ankle. The treatment is removal of the foreign body by a surgical operation.

\section{LOOSE CARTILAGES}

Within the knee joint there are two crescent shaped dises of cartilage known as the semilunar cartilages (internal and external). They are attached to the upper surface of the head of the tibia and to the capsule of the joint. Due to a wrench or strain of the knee joint one or both of these cartilages may become detached and cause a severe disability of the knee.

Loose Cartilages of the knee joint give practically the same symptoms as floating bodies, and the differential diagnosis between the two conditions is often very difficult. The treatment of loose cartilages of the knee 
joint is first to manipulate them back into place and then support the knee until the cartilages become fixed. If, as sometimes happens, the cartilages do not reattach themselves, but remain loose, it is necessary to remove them to prevent the constant annoyance of having them get caught between the bones.

\section{The Foot}

One of the most important acquired disabilities and deformities of the foot is weak foot, but that particular disability and deformity will be discussed in a chapter by itself.

There are numerous congenital deformities of the foot, which can be recognized when seen; one of these is what is known as lobster claw deformity. No discussion is necessary. The most important congenital deformity of the foot is club foot, which has already been discussed.

\section{ACQUIRED CLUB FOOT}

Acquired Club Foot is usually due to paralytic disease; the foot being drawn into a deformed position by the action of unopposed muscles or by contractures The treatment is operative.

\section{- PIGEON TOE}

Pigeon Toe is a deformity rather common in children, and in a great many cases it is due to the fact 
that the child is suffering from weak arches. The toeing in is the result of Nature's effort to raise the arch of the foot. This can be easily illustrated by turning in the toes, when it will be seen that the arch of the foot is raised. Mild eases of toeing in will clear up of themselves. Supporting the weakened arches of the feet will cure other cases. When the toeing in is a habit and not due to weak arches, building up the outer edge of the sole of the shoe will stop it.

\section{The Heel}

\section{BURSITIS}

Bursitis, sometimes known as "policeman's heel," is a disability that may be present in people who walk or stand a great deal on hard surfaces. Just as in the shoulder and knee, the bursa under the heel becomes inflamed and causes very severe pain when pressure is put upon it. The treatment is rest, removal of the weight of the body from the heel by the use of arch supports, and in persistent cases removal of the sac of the bursa.

\section{EXOSTOSIS OF THE OS CALCIS}

Lxostosis of the Os Calcis is the name given to a small spicule of bone growing out from the under surface of the heel bone (the os calcis-see Fig. 62). The cause of the exostosis is variable: it may follow an injury or an acute infectious disease such as influenza, or it may 
be a reaction to constant irritation, like standing day after day on a hard cement floor. The principal symptom of exostosis of the os calcis is a pain underneath and to the imner side of the heel every time weight is

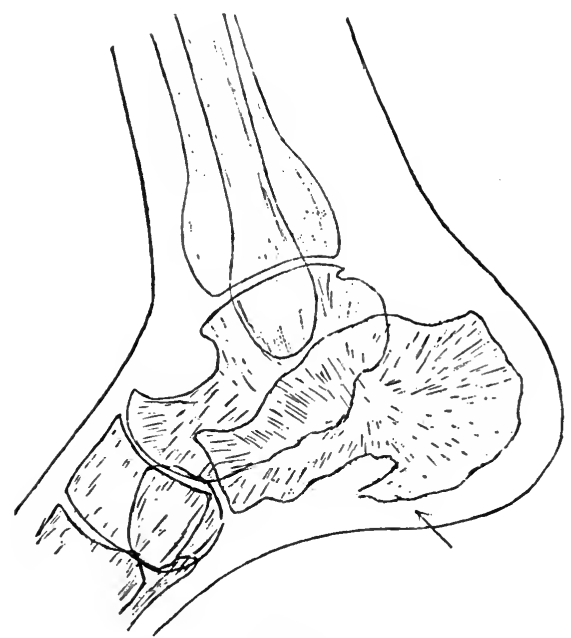

Fig. 62.

Exostosis of the os calcis. The arrow points to the exostosis, which is an unusually large one.

borne on the foot. On standing there is a burning, sticking pain in the heel. The treatment is to remove the exostosis.

\section{The Toes}

Congenital malformations consist of webbed toes, missing toes, extra toes, etc.

The great toe is subject to three structural deformities known as: 
Hallux valgus (toe turned out).

Hallux varus (toe turned in).

Hallux rigidus (toe turned up or down and held rigid).

\section{HALLUX VALGUS}

IIallux Valgus, or bunion, which is the common name for the deformity, is the most frequent deformity of the great toe. It is a condition usually associated with "weak feet," and is often caused by wearing shoes too

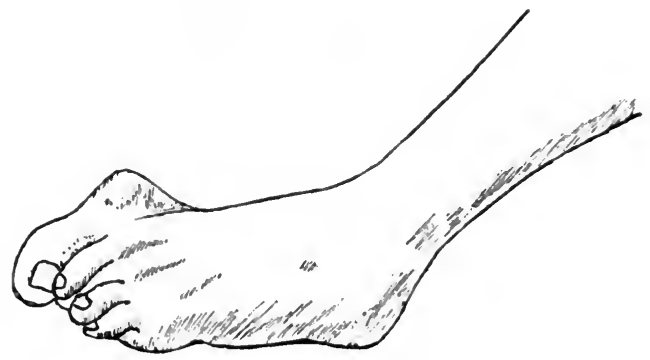

Fig. 63.

Hallux valgus (bunlon).

narrow across the ball of the foot or with too pointed a toe (Fig. 71). It is a "fashion deformity." The great toe is turned outward and the metatarsophalangeal joint becomes enlarged, painful and inflamed, forming a bunion (Fig. 63).

The treatment is, first of all, to supply the patient with proper shoes-shoes that do not compress the ball of the foot or turn the great toe outward. In some 
cases an arch support which removes some of the weight of the body from the inflamed joint will effect a cure. Radical treatment consists in removing the head of the first metatarsal bone. When properly performed this is a very satisfactory operation.

\section{HALLUX VARUS}

Hallux Varus (Fig. 64) is frequently a congenital deformity, but may be caused by paralytic diseases. The treatment is surgical.

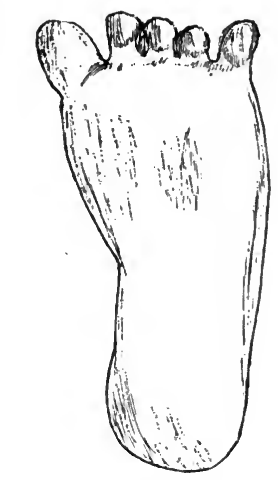

Fig. 64 .

Hallux varus (congenital).

\section{HALLUX RIGIDUS}

Hallux Rigidus is, properly speaking, a form of osteo-arthritis, but is also frequently associated with "weak-feet." The bony edges of the great toe joint become roughened and bony spicules may form, and the 
joint becomes painful and more or less ankylosed (Fig. $65)$.

In very mild cases treatment may consist in stiffening the sole of the shoe underneath the inflamed joint, thus preventing excessive motion. In severe cases it is necessary to operate and resect the joint.
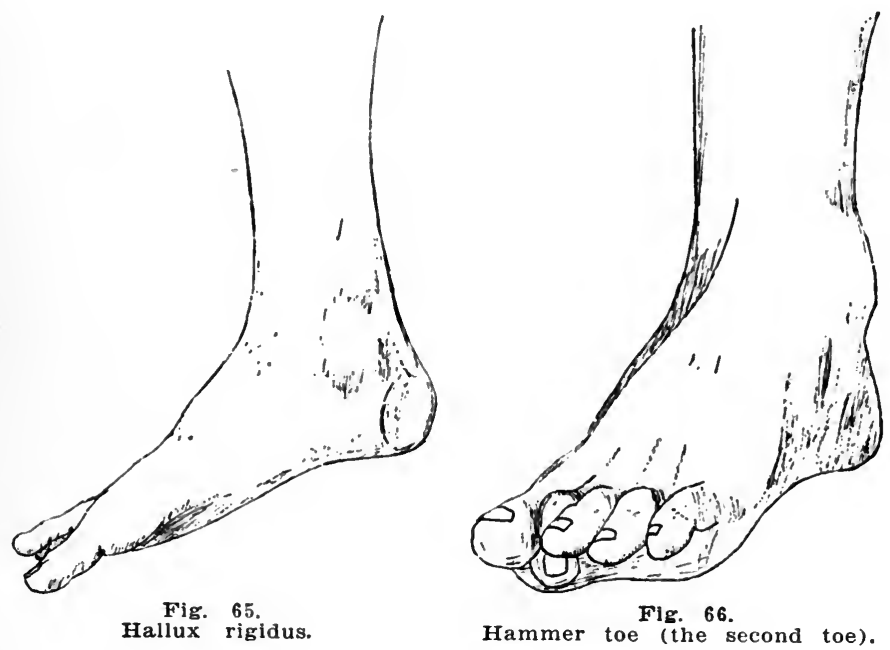

HAMMER TOE

Hammer Toe (Fig. 66) is due to a drawing up of one toe, a contraction of the ligaments and tendons. It may be congenital or may be associated directly or indirectly with "weak feet."

In children a cure can sometimes be obtained by cutting the contracted tissues and keeping the toe 
straight in a splint for some time. In adults it may be best to remove the offending toe.

\section{TRIGGER TOE}

Trigger Toe has the same causes, symptoms and treatment as trigger finger, which has already been discussed.

\section{ANTERIOR METATARSALGIA AND MORTON'S TOE}

The heads of the metatarsal bones form what is known as the anterior arch of the foot, and, when this arch is strained or depressed, it causes a pain in the
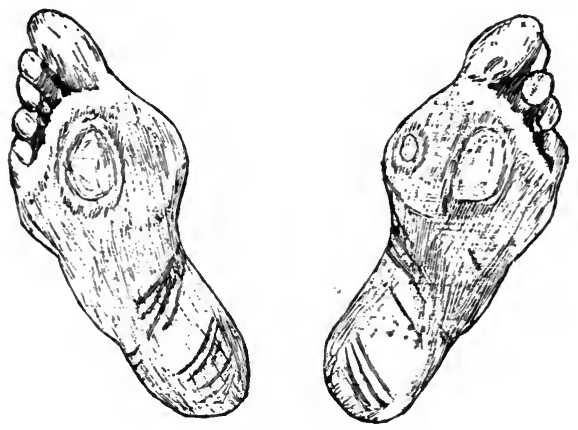

Fig. 67.

Callus formation on sole of feet in anterior metatarsalgia.

front part of the foot known as Anterior Metatarsalgia. Evidence of the depressed anterior arch is frequently shown by callus formation on the ball of the foot (Fig. $67)$. 
Morton's Toe is a severe pain or cramp in one of the toes, more often the fourth. It comes on while the patient is walking, and is sometimes so severe that the patient has to stop, remove the shoe and massage the foot. It is supposed to be due to the head of the metatarsal bone pressing on a nerve.

In mild cases relief may be obtained by supporting the heads of the metatarsal bones by an anterior arch support. In severe cases it is necessary to remove the head of the metatarsal bone causing the trouble. 


\section{CHAPTER V}

\section{WEAK FEET}

A nurse in training sooner or later realizes the importance of having her feet always in proper condition. Ordinarily she is apt to forget and neglect her feet, packed away, as they are, in leather cases at the farthest possible distance from her brain centers; but they are nevertheless very important parts of her body. They deserve her constant care and attention, for if they suffer, her whole body will suffer with them.

Foot troubles are almost unknown among bare-footed savages, but in our modern civilization practically the only examples of perfect feet are found in babies. The great majority of babies have perfect feet. Some unfortunate babies are born with deformed feet or suffer from paralyzing and deforming diseases later, but such cases have already been discussed. The fact is that most individuals begin life with normal feet. Why then is foot trouble so prevalent?

Dr. Hoffman, an orthopedic surgeon in St. Louis, at the time of the World's Fair, experimented with the feet of bare-footed savages. He supplied the savages with what seemed to be perfectly fitting modern footwear and found that in a very short time all the savages began to experience more or less foot trouble. 
Some one unknown to the writer has composed a "limerick" which goes something like this:

A dashing young brave of the Sioux

Tried to walk in a paleface's shoc;

But it caused so much woe

To his primitive toe,

Ire stopped it without much ado.

The conclusion is that the modern shoe is the prime factor in causing foot troubles. Why is this so?

The foot is a complicated structure made up of numerous bones, ligaments, muscles, bloodvessels, nerves, etc., all moulded together to form a support to the body, strong and steady, and yet at the same time flexible and capable of motion. Mechanically considered, the foot is a wonderful piece of machinery.

It can readily be understood how detrimental it would be to an intricate machine to have anything interfere with its proper working; how easily under such conditions its parts could be injured and strained and its strength and efficiency impaired. Now just that sort of thing can happen to the foot and that is just the state of affairs when it is compelled to work in a faulty shoe.

A shoe may be faulty in various ways. The heel may be too high or too low, throwing the weight of the body too far forward or too far back. The inner sole of the shoe may not be large enough to support the weight-bearing surface of the foot (Fig. 68). The shoe may exert undue pressure at some points, allowing too much play at other points and be very un- 
comfortable in consequence. Lastly, the shape of the shoe may be such that the foot is held in an abnormal position that tends to eause deformity. Each and all of these features of a faulty shoe cause a constant strain and loss of strength and efficiency in the working foot.
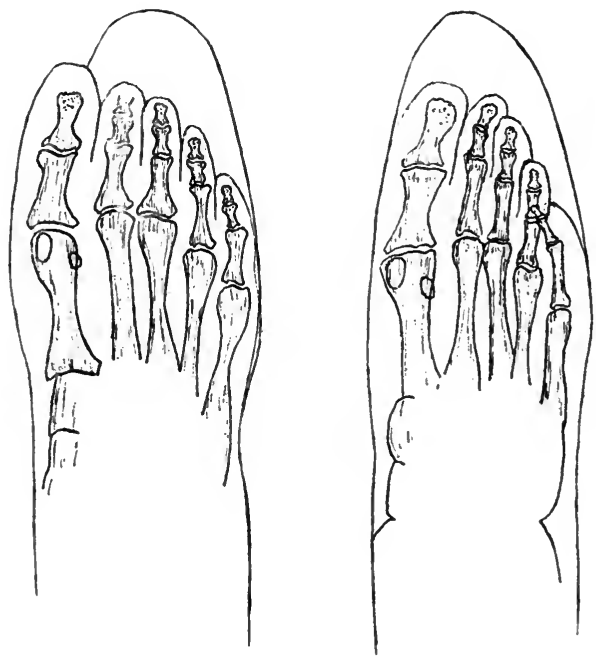

Fig. 68.

Illustration of a faulty shoe. The inner sole of the shoe is not large enough to accommodate the foot. The figure on the right shows the foot compressed in the shoe outline. The figure on the left shows the position that the foot takes when the upper of the shoe is cut away.

Fortunately the foot is naturally strong and is usually able to resist these injuries and strains for a long time. When, however, in addition to the effect of a faulty shoe, there is an added effect of increased weight of the body, excessive use of the feet, a debilitat- 
ing illness weakening the muscles and ligaments, or direct injury to the foot, such as a severe sprain or contusion, the foot gives way and the symptoms of "weak feet" begin.

Corns, calluses and a tired feeling are nature's danger signals to the feet, but how often they are disregarded. Corns and calluses are more often considered as a matter of course, notwithstanding the fact that there is no more reason why a foot should have corns than that a baby should have pimples. Both show that something is wrong. Tired feeling in the feet and the nervous irritability that goes with it are frequently attributed to every condition except the true one. Many cases of so-called laziness, loss of ambition, bad temper, incompatibility of temperament in the married state, etc., may in reality be beginning "weak feet."

Aside from the danger signals, pain is the first symptom of "weak feet." The pain may be located in the longitudinal arch of the foot, in the ball of the foot, in the ankle or in fact almost anywhere in the foot. In some cases pain first shows itself in the leg, knee, thigh or even in the back. The cause of the pain in the early stage of "weak feet" is muscular or ligamentous strain.

An examination of the foot at this time may show an abnormal position during weight bearing. The foot may be turned outward, rolled in at the ankle, prominent inward and downward at the instep (Fig. $69)$, or flattened across the ball with marked callus formation (Fig. 67) -all evidences of the strained condition of the longitudinal and anterior arches. 
Sometimes the effect of strain on the foot is to cause irritability and spasm of the muscles and the foot becomes contracted rather than flat. The longitudinal arch becomes abnormally high and the toes are drawn up like claws. This is the condition known as contracted foot and is frequently associated with the use of shoes with too high a heel (Fig. 70).

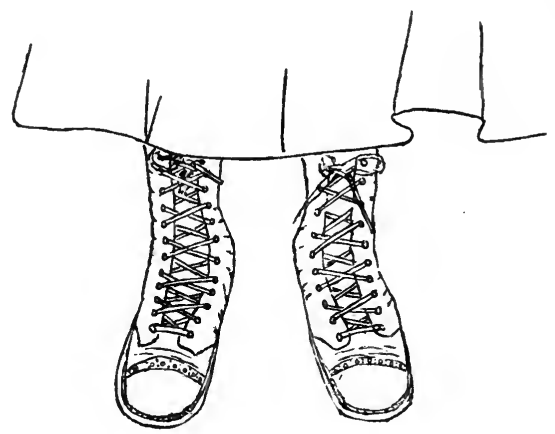

Fig. 69.

Weak feet.

Hallux valgus, Morton's toe and hammer toe, conditions already discussed, may develop at this and other stages of "weak feet."

In all cases of "weak feet," as the strain continues the pain increases. The foot becomes swollen and tender to the touch, muscular spasm and cramps may be present and the appearance of the foot is such that a diagnosis of rheumatism or even tuberculosis may be 
made. Later still, actual bony deformity, an acquired club-foot, occurs, and walking becomes almost impossible.

Such, in brief, is the description of the downward path of the weak-footed. How shall the individual avoid such a fate; or, having once started on the broad way that leads to destruction, how shall he regain a strong foothold?

First of all, if he cannot save himself he may at

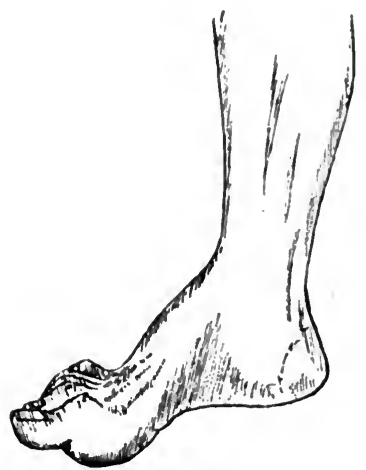

Fig. 70.

Contracted foot.

least save others. Children should be protected against the strain of faulty shoes. Babies' shoes should be large enough-fortunately almost all baby shoes on the market are of good shape. Growing girls and boys should be instructed to stand and walk with the feet straight ahead and the shoes should conform in shape to orthopedic principles, having broad toes, sufficient width at 
the ball of the foot, very moderately high heels with the general shape such that the foot is held in a perfectly natural position and not with the front part turned outward, as is apt to be the case in straight-last narrow-toed shoes (Fig. 71). Probably the greatest

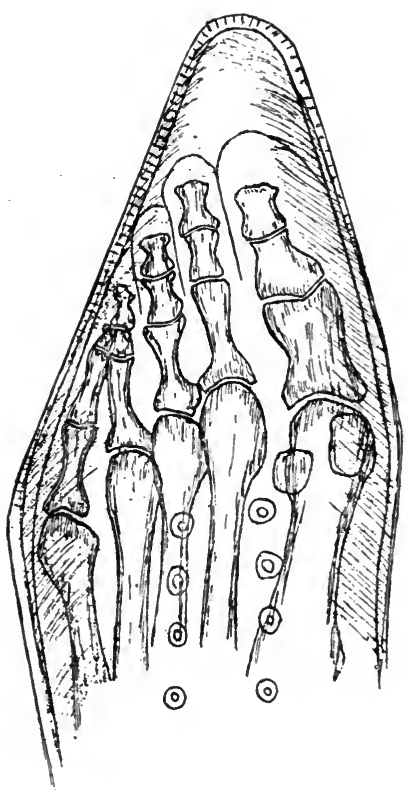

Fig. 71.

Faulty shoe causing hallux valgus.

danger to the feet comes at the age when a boy begins to call on his "best girl" and when a girl begins to attend parties. There is a desire to make the feet look small and smart and all manner of faulty footwear 
are forced upon the unwilling but yielding extremities. It is at this critical time, when the feet are not fully developed and are still very susceptible to deforming influences, that much harm is done, the effects of which may not show until later.

In adult life the foot is not so susceptible to deforming influences. The wearing of faulty shoes calls attention to itself much quicker by causing pain; but if persisted in, the effects are the same as in younger people. The slogan for preventing "weak feet" at all ages is: "Wear proper shoes."

After foot trouble has started, the first procedure to obtain relief is to provide proper shoes. Then, if possible, remove the contributing cause (excessive weight, excessive use, etc.), practice correct walking and standing with the feet straight ahead, not turned outward (Fig. 72), and take special exercises to strengthen the foot, such as rising on tip-toe and coming down on the outer side of the foot. A simple procedure and one that rests tired feet a great deal is to sit with the feet crossed, the weight resting on the outer side. Building up the inner side of the sole of the shoe, so as to throw the weight to the outer side of the foot is often very effectual in relieving foot strain. In early cases of "weak feet" the above measures will effect a cure.

When the strain on the foot is more acute or more pronounced, it may be necessary to manipulate the foot and strap it into an overcorrected position as a preliminary to the above-described procedures. Strap- 
ping the foot into the adducted or overcorrected position relieves the strained muscles and ligaments and gives the foot a chance to recover its strength. When the strain on the foot is still greater, and cannot be relieved by strapping, it is necessary to have an arch
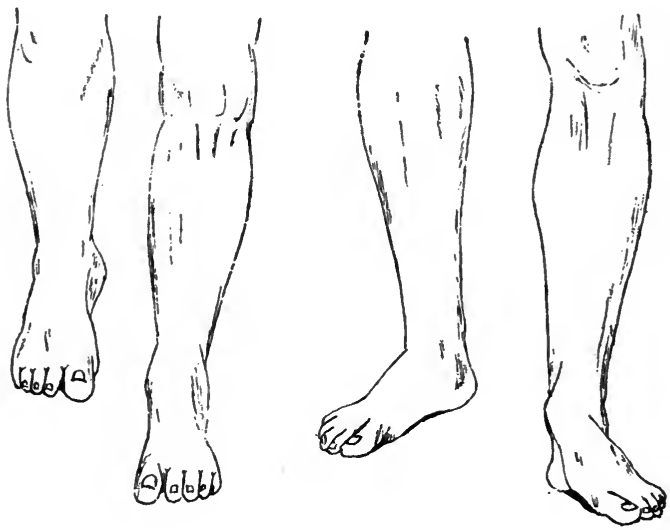

Fig. 72.

Proper and improper position of the feet in walking. When the feet are held straight ahead the line of body weight falls through the center of the knee, ankle and foot and the greatest amount of strength and efficiency is attained. When the feet are turned outward the line of body weight falls to the inner side and the arch of the foot is constantly strained and the strength and efficiency of the foot suffer in consequence (After Whitman).

support made. The arch support holds the foot in its correct position and allows it to work and strengthen itself without strain. In conditions associated with pain, swelling, tenderness, muscle spasm and deformity, it is sometimes necessary to correct the deformity under ether and put the foot in a plaster-of-Paris cast for a 
time. Such cases should wear arch supports after the cast is removed.

In the severest type of "weak feet" a condition known as rigid flat-foot, where actual bony deformity and distortion have taken place, it is almost impossible to effect a cure. Operative interference and the wearing of arch supports are sometimes of benefit, but the prognosis is always doubtful. 


$$
\text { • }
$$




\section{INDEX}

Abdomen, appearance of, in rickets, 26 enlargement of, in rickets, 25

Abnormally formed bones, deformity from, 23 placed bones, deformity from, 23

Abscess formation in bone tuberculosis, 38

Acetabulum, 17

Acquired club-foot, 68

deformities, 11

caused by disease, 24 wry-neck, 44

Adhesive strapping in talipes, 16

Anterior poliomyelitis, 29 . See also Infantile Paralysis Arch supports for hallux valgus, 72

for weak feet, 84

Arthritis, chronic deforming,

41

rheumatoid, 42

Asymmetry of development, 22

unilateral, 23

Athetoid movements in birth palsy, 32

Atrophy in birth palsy, 32
Atrophy in infantile paralysis, 30

Bacillus tuberculosis, 32 Birth palsy, 31

athetoid movements in, 32

atrophy in, 32

causes, 32 characteristic attitude in, 31

feeble-mindedness in, 32 infantile paralysis and, 32

loss of co-ordination in, 32

prognosis, 32

spasm in, 31

symptoms, 32

treatment, 32

Bloodless method of treatment for dislocation of hip, 18,19

Bone tuberculosis, 32. See also Pott's disease

Bradford frame in, 39

cause, 32

deformity in, 33

cause of, 38.

discharging sinus in, 38

fresh air in, 39

good food in, 39 
Bone tuberculosis, muscle spasm in, 33

night cries in, 34

operative treatment, 41

pain in, 33

prognosis, 38, 41

proper diet in, 39

recognition of, 38

rest in, 39

running sores in, 38

symptoms, 33

tenderness in, 33

treatment, 39

Whitman frame in, 39

wry-neck from, 44

Bones, abnormal growth of, in rickets, 25

softness of, 25,27

cartilage of, 25

composition of, 24

epiphyses of, 25

formed abnormally, 23

lime salts of, 24

missing, 23

ossification of, 25

placed abnormally, 23

supernumerary, 23

Bowing of legs, anterior, 65

Bow-legs, 63, 64

anterior, 65

in rickets, $26,27,28$

Braces for Pott's disease, 42

in infantile paralysis, 30

Bradford frame, 39,40

Bunion, 71. See also Hallux valgus

Bursitis, 69
Bursitis, prepatellar, 66

subdeltoid, 56,57

Calluses, 79

Cartilage, loose, in knee-joint, 67

of bones, 25

Cervical rib, 44,45

location, 45

treatment, 45

Chest, deformities of, 45

Club-foot, 12. See also

Talipes

acquired, 68

Congenital club-foot, 14

deformities, 11

dislocation of hip, 17

malformation of toes, 70

orthopedic deformities, 12

wry-neck, 21. See also

Torticollis

Contracted feet, 80

Contractions in tuberculosis of knee, 37

Contracture, Dupuytren's, 60 in infantile paralysis, 29

Convulsions in infantile paralysis, 29

Co-ordination, loss of, in birth palsy, 32

Corns, 79

Curvature, lateral, of spine, 50. See also Scoliosis

Deforming arthritis, chronic, 41

Deformities, acquired, 11 
Deformities caused by disease, 24

cause of, in bone tuberculosis, 38

congenital, 11 contracture, in infantile paralysis, 29,30

early recognition of, 23 from missing bones, 23 from softness of bones, 28 in bone tuberculosis, 33 in hip tuberculosis, 36 in Pott's disease, $33-37$ in rheumatoid arthritis, 43 in weak feet, 81,85

of chest, 45

of feet, 68

of fingers, 59

of hand, 57

of hip, 63

of neck, 44

of pelvis, 62

of shoulder, 54

of spine, 47

of toes, 70

of wrist, 57 .

orthopedic congenital, 12

examples of, 11

postural, in rickets, 27,28

regional, 44, 62

spinal, in rickets, 27

structural, of knee, 63

swelling, in tuberculosis of

knee, 37

Dentition, delayed, in rickets, 27

Development, asymmetry of, 22
Diet in bone tuberculosis, 39

Disabilities of feet, 68

of elbow, 57

of heel, 69

Dislocation of hip, congenital, 17

characteristic attitude

in, 19

characteristics of, 17

course when untreated, 18

double, lordosis in, 49

duck-like waddle in, 17

frequency of, 17

frog position of cast in,

19,20

gait in, 17

importance of early

treatment in, 20

plaster-of-Paris cast for, 19

prognosis in, 20

recognition of, 17

symptoms, 17

treatment, 18, 19

by bloodless method,

18,19

by Lorenz method, 18,19

by open method, 18 , 19

$x$-ray picture of, 18

of shoulder, congenital, 54

characteristic attitude

in, 54

obstetric paralysis and, 55 
Dorsal spine, tuberculosis of, 34

Dupuytren's contracture, 60 causes, 60

treatment, 60

Elbow, disability of, 57 tennis, $\mathbf{5 7}$

Electricity in infantile paralysis, 30

Enteroptosis from lordosis, 49

Epiphyses of bones, 25

in rickets, 26

Exercises for scoliosis, 53

for weak feet, 83

Exostosis of os calcis, 69 causes, 69

from influenza, 69

symptoms, 70

treatment, 70

Faulty shoes, 77 examples of, 78

Feeble-mindedness in birth palsy, 32

Feet, contracted, 80

deformities of, 68

disabilities of, 68

effects of strain on, 80

healthy, importance of, 76

improper position of, in walking, 84

mechanism of, 77

of savages, Hoffman's experiments on, 76

proper position of, in walking, 84
Feet, resistant powers of, 78 troubles, among savages, 76

from modern shoes, $77^{\circ}$

prevalence of, 76

weak, 76. See also Weak feet

Fever in infantile paralysis, 29

in rheumatoid arthrits, 43

Finger, mallet, 61

trigger, 61

deformities of, 59

Flat-foot, rigid, 85

Floating bodies in knee-joint, 67

Fontanelle, anterior, in rickets, 26

Foot, club, 12. See also Talipes

effect of talipes on development of, 15

troubles, prevalence of, 76

Forehead, shape of, in rickets, 26

Fresh air in bone tuberculosis, 39

in scoliosis, 53

Frog position of cast in dislocation of hip, 19, 20

Funnel-chest, 47

causes, 47

Gaxglion of wrist, 59

Genu recurvatum, 65

valgum, 63,64

varum, 63,64

Groove, Harrison's, 46

Growing pains in children, 38 
Hallux rigidus, 72 treatment, 73 valgus, 71

arch supports in, 72 causes, 71

from faulty shoes, 82

from weak feet, 80 operative treatment, 72 treatment, 71

varus, 72

Hammer-toe, 73

causes, 73

from weak feet, 80

treatment, 73,74

Hand, deformities of, 57

Harrison's groove, 46

Heberden's nodes, 41

Heel, disability of, 69

policeman's, 69

Hip, deformities of, 63 dislocation of, congenital, 17. See also Dislocation of hip, congenital tuberculosis of, 35. See also

Tuberculosis of hip

Hoffman's experiments on feet of savages, 76

Hot compresses in acquired wry-neck, 44

Housemaid's knee, 66

causes, 66

treatment, 66

Hunch-back, 49

INFANT feeding, importance of, 25

recognition of club foot in, 15
Infantile paralysis, 29

atrophy in, 30

and birth palsy, difference, 32

braces in, 30

contracture deformity in,

29,30

contracture in, 29

convulsions in, 29

electricity in, 30

fever in, 29

flaccid type, 29

germ origin of, 29

massage in, 30

muscle training in, 30

surgical treatment, 30

symptoms, 29

treatment, 30

Influenza, exostosis of os calcis from, 69

Ischemic paralysis, Volkmann's, 58

Italian children, rickets in, 24

Jorst swelling in rheumatoid arthritis, 43

Joints, tuberculosis of, 37

KNEE, housemaid's, 66

structural deformities of, 63

tuberculosis of, 37. See also

Tuberculosis of knee

Knee-joint, floating bodies, $\mathbf{6 7}$

loose cartilages in, 67

senile osteo-arthritis in, 41

Knock-knee, 63, 64 
Kyphosis, 48

in Pott's disease, 36,48

in rickets, 27

lordosis secondary to, 49,50 rounded, in spondylitis de-

formans, 54

treatment, 49

LIME salts of bones, 25

Little's disease, 31. See also Birth palsy

Liver, enlargement of, in rickets, 26

Loose cartilages in knee-ioint, 67

Lordosis, 49

enteroptosis from, 49

in double congenital dislocation of hip, 49

in rickets, 25,26

secondary to kyphosis, 49, 50

treatment, 50

Lorenz method of treatment of dislocation of hip, 18, 19

MALLET-FINGER, 61

cause, 61

treatment, 61

Massage in infantile paraly. sis, 30

in obstetric paralysis, 56

Metatarsalgia, anterior, 74

causes, 74

treatment, 75

Missing bones, deformity from, 23
Morton's toe, 75

causes, 75

from weak feet, 80 treatment, 75

Muscle spasm in bone tuber. culosis, 33

in hip tuberculosis, 36

in Pott's disease, 35

in tuberculosis of knee, 37

training in infantile paralysis, 30

Muscular exercises in scoliosis, 53

for weak feet, 83

NECK, deformities of, 44

stiff, 44. See also Wry-neck, acquired

Negro children, rickets in, 24

Night cries in bone tuberculosis, 34

Obstetric paralysis, causes, 55

characteristic attitude in, 55

congenital dislocation of shoulder and, 55

involvement of arm in, 56

massage in, 56

operative treatment, 56

rupture of nerve-trunks in, 55

treatment, 56

Open method of treatment of dislocation of hip, 18, 19 
Orthopedic deformities, congenital, 12

examples of, 11

surgery, definition of, 11

Os calcis, exostosis of, 69

Ossification, 25

Osteo-arthritis, senile, 41

Heberden's, nodes in, 41

in knee-joints, 41

parts affected by, 41

prevalence of, 41

spinal form, 53. See also

Spondylitis deformans, treatment, 42

Overcorrection in wry-neck, 21,22

PaIn in hip tuberculosis, 35

in Pott's disease, 34

in tuberculosis of bones, 33 of knee, 37

in weak feet, 79

Pains, growing, 38

Palsy, birth, 31

Paralysis, infantile, 29

obstetric, 55

spastic, 31. See also Birth palsy.

Volkmann's ischemic, 58

Pelvis, deformities of, 62

Pigeon breast, 47

causes, 47

Pigeon-toe, 68

walk in equinovarus, 15

Plaster-of-Paris casts for scoliosis, 53

for tuberculosis of spine, 40
Plaster-of-Paris casts for weak feet, 84

in bone tuberculosis, 39 , 40

in congenital dislocation of hip, 19

in talipes, 16

in torticollis, 21, 22

Poker-back, 54

Policeman's heel, 69

Poliomyelitis, anterior, 29.

See also Infantile paralysis

Posture, faulty, scoliosis from, 50

Pott's disease, brace for, 42

characteristic attitude in, $33-37$

deformity in, $33-37$

kyphosis in, 36,48

muscle spasm in, 35

pain in, 34

plaster-of-Paris casts for, 40

symptoms, 34

tenderness in, 35

Prepatellar bursitis, 66

Puberty, scoliosis at, 50

RACHITIC rosary, 26,46

wry-neck, 44

Rachitis, 24. See also Rickets Rapid growth, scoliosis from, 50

Regional deformities, 44, 62

Resistant powers of feet, 78

Rest in bone tuberculosis, 39 in scoliosis, 53 
Rheumatism, wry-neck from, 44

Rheumatoid arthritis, 42 causes, 42

deformity in, 43

fever in, 43

from tonsillitis, 42

from neglected teeth, 42

surgical treatment, 43

sweating in, 43

swelling of joints in, 43

symptoms, 42

treatment, 43

Ribs, beaded, in rickets, 26

Rib, cervical, 44, 45

Rickets, 24

abnormal growth of bones in, 25

softness of bones in, 25

anterior fontanelle in, 26

appearance of abdomen in, 26

beaded ribs in, 26

bow-legs in, 26,28

causes, 24

delayed dentition in, 27

enlargement of abdomen in, 25

of liver in, 26

epiphyses in, 26

forehead in, 26

from improper food, 24,25

kyphosis in, 27

lordosis in, 25, 26

postural deformity in, $2 \%$, 28.

prevalence among poor, 24 prognosis in, 28
Rickets, proper feeding for, 28

retarded development in, 27 shape of forehead in, 26 spinal deformity in, 27 sweating of head in, 25 symptoms of, 25 treatment, 28 wry-neck from, 44

Rickety rosary, 26, 46

Round shoulders, 48. See als3 Kyphosis

Running sores in bone tuberculosis, 38

Sacro-Illac joints, strain of, 62

symptoms, 63 treatment, 63

Savages, foot troubles among, 76

Scoliosis, 50

advanced stage, 52

at puberty, 50

causes, 50

conditions associated with, 53

course of, 51,52

early stages, 51

effects of, on general health,

51

fresh air in, 53

from faulty posture, 50

from rapid growth, 50

importance of early recog-

nition of, 53

muscular exercises in, 53

plaster-of-Paris casts in, 53 
Scoliosis, pressure on spinal nerve trunks in, 52 prevalence in girls, 50 rest in, 53

S-shaped curve of spine in. 51

structural deformity in, 52 symptoms, 50

tonics in, 53

treatment, 53

Senile osteo-arthritis, 41

Shoes, faulty, 77, 82

examples of, 78

hallux valgus from, 82

modern, foot troubles from,

77

proper, for weak fcet, 83

for young, 81

Shoulder, congenital dislosation of, 54

deformities of, 54

Shoulders, round, 48. See also Kyphosis

Sinus, discharging, in bone tuberculosis, 38

Spasm in birth palsy, 31

Spastic paralysis, 31. See also Birth palsy

Spinal deformity in rickets, 27

nerve-trunks, pressure on, in scoliosis, 52

tuberculosis, 34 . See also Pott's disease

Spine, bending forward of, 49 deformities of, 47 lateral curvature of, 50

See also Scoliosis
Spine, S-shaped curve of, in scoliosis, 51

Spondylitis deformans, 53

characteristic attitude in, 53

pokēr-back in, 54

rounded kyphosis in, 54 treatment, 54

Sternocleidomastoid muscle, contraction of, 21

Stiff neck, 44. See also Wryneck, acquired

Strain, effects of, on feet, 80 of sacro-iliac joints, 62

Subdeltoid bursitis, 56, 57

Supernumerary bones, deformity from, 23

Surgery, orthopedic, definition of, 11

Sweating in rheumatoid arthritis, 43

in rickets, 26

TALIPES, adhesive strapping in, 16

calcaneus, 12, 13

combinations of, 14

congenital, 14

danger of relapse in, 16 early recognition of, 16 early treatment for, 16 effects of, on development of feet, 15

equinovarus, 14

pigeon-toe walk in, 15

symptoms, 15

equinus, 12,13

from weak feet, 81 
Talipes, hereditary, 12 importance of thorough treatment in, 15,16 manipulative correction of, 16

plaster-of-Paris cast for, 10 recognition of, in infants,

15

symptoms, 15

treatment, 15

of mild cases, 16

of neglected cases, 17

of resistant cases, 16

of severe cases, 16

valgus, 13,14

varieties of, 12,13

varus, 12,13

Teeth, ulcerated, rheumatoid arthritis from, 42

Tennis elbow, 57

Toe, congenital malformation of, 70

deformities of, 70

hammer, 73

Morton's, 75

trigger, 74

Tonics in scoliosis, 53

Tonsillitis, rheumatoid arthritis from, 42

Torticollis, 21

after-treatment for, 22

cause of, 21

correctve manipulation of,

21

overcorrection for, 21

Traumatism, wry-neck from, 44

Trigger finger, 61
Trigger finger, cause, 61

treatment, 61

Trigger toe, $\mathbf{7 4}$

Tubercle bacillus, 32

Tuberculosis of bones, 32 . See also Pott's disease

of cervical spine, 33

of dorsal spine, 34

of hip, 35 .

characteristic attitude in, 37,38

deformity in, 36

muscle spasm in, 36

pain in, 35

symptoms, 35

tenderness in, 35

of joints, 37

of knee, characteristic appearance, 39

contractions in, 37

deformity swelling in, 37

muscle spasm in, 37

pain in, 37

tenderness in, 37

of spine, 34. See also Pott's disease

Volkmanx's ischemic paralysis, 58

causes, 58

treatment, 59

WALKIXG, improper position of feet in, 84

proper position of feet in, 84

Weak feet, 76,80

advanced, 80 
Weak feet, arch support for, 84

associated with other conditions, treatment, 84 club-foot from, 81

condition s associated with, 79

deformity in, 81,85

examination of, 79

hallux valgus from, 80

hammer toe from, 80

how to rest, 83

Morton's toe from, 80

operative treatment, 85 orthopedic treatment, 83 pain in, 79

plaster-of-Paris casts in,

84

prevention of, 83

in young, 81

prognosis, 85

proper shoes for, 83
Weak feet, severest type, 85 special exercises for, 83 symptoms of, 79 treatment, 83

Weeping sinew, 59

Whitman frame, 39, 40

Wrist, deformities of, 57

ganglion of, 59

Wry-neck, acquired, 44

causes, 44

from bone tuberculosis 44

from catching cold, 44

from rheumatisn, 41

from rickets, 44

from traumatism, 44

hot compresses for, 44

treatment, 44

congenital, 21. See also

Torticollis

rachitic, 44 


\section{Books for Nurses}

PUBLISHED BY

\section{W. B. SAUNDERS COMPANY West Washington Square \\ Philadelphia}

London: 9, Henrietta Street, Covent Garden

\section{Sanders' Nursing a NÉW WORK}

Miss Sanders' new book is undoubtedly the most complete and most practical work on nursing ever published. Every thing about every subject with which the nurse should be familiar is detailed in a clean cut, definite way. There is no other nursing book so full of good, practical information-information you need.

Modern Methods in Nursing. By Georgiana J. SAnders, formerly Superintendent of Nurses at Massachusetts General Hospital. $12 \mathrm{mo}$ of 881 pages, with 227 illustrations.

Cloth, \$2.50 net.

\section{Dunton's Occupation Therapy}

\section{JUST ISSUED}

Dr. Dunton gives those forms likely to be of most service to the nurse in private practice. You get chapters on puzzles, reading, physical exercises, card games, string, paper, wood, plastic and metal 'work, weaving, picture puzzles, basketry, chair caning, bookbinding, gardening, nature study, drawing, painting, pyrography, needlework, photography, and music.

Occupation Therapy for Nurses. By WILliam RUSH Dunton, Jr., M. D., Assistant Physician at Sheppard and Enoch Pratt Hospitals, Towson, Md. ramo of 240 pages, illustrated. Cloth, $\$ 1.50$ net. 


\section{Stoney's Nursing}

Of this work the American Journal of Nursing says: "It is the fullest and most complete and may well be recommended as being of great general usefulness. The best chapter is the one on observation of symptoms which is very thorough." There are directions how to improvise everything.

Practical Points in Nursing. By EMILY M. A. STONEY, formerly Superintendent of the Training School for Nurses in the Carney Hospital, South Boston, Mass. I2mo, 495 pages, illustrated. Cloth, \$r.75 net.

\section{Stoney's Materia Medica}

NEW (3d) EDITION

Stoney's Materia Medica was written by a head nurse who knows just what the nurse needs. American Medicine says it contains "all the information in regards to drugs that a nurse should possess."

Materia Medica for Nurses. By Emily M. A. Stoney, formerly Superintendent of the Training School for Nurses in the Carney Hospital, South Boston, Mass, I2mo volume of 300 pages. Cloth, \$r.50 net.

\section{Stoney's Surgical Technic}

NEW (3d) EDITION

The first part of the book is dovoted to Bacteriology and Antiseptics; the second part to Surgical Technic, Signs of Death, Bandaging, Care of Infants, etc.

Bacteriology and Surgical Technic for Nurses. By EMILY M. A. Stoney. Revised by Frederic R. Griffith, M. D., New York. ramo volume of 3 Ir pages, fully illustrated. Cloth, \$r.50 net.

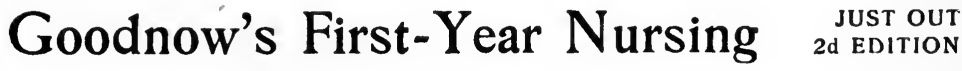

Miss Goodnow's work deals entirely with the practical side of first-year nursing work. It is the application of text-book knowledge. It tells the nurse how to do those things she is called upon to do in her first year in the training school-the actual ward work.

First-Year Nursing. By MinNiE Goodnow, R. N., formerly Superintendent of the Women's Hospital, Denver. I2mu of 354 pages, illustrated.

Cloth, \$r. 50 net. 


\section{Aikens' Hospital Management}

This is just the work for hospital superintendents, trainingschool principals, physicians, and all who are actively interested in hospital administration. The Medical Record says: "Tells in concise form exactly what a hospital should do and how it should be run, from the scrubwoman up to its financing."

Hospital Management. Arranged and edited by Charlotte A. AIKENS, formerly Director o! Sibley Memorial Hospital, Washington, D. C. $12 \mathrm{mo}$ of 488 pages, illustrated.

Cloth, $\$ 3.00$ net

\section{Aikens' Primary Studies}

Trained Nurse and Hospital Review says: "It is safe to say that any pupil who has mastered even the major portion of this work would be one of the best prepared first year pupils who ever stood for examination."

Primary Studies for Nurses. By Charlotte A. Aikens, formerly Director of Sibley Memorlal Hospital, Washington, D. C. $12 \mathrm{mo}$ of 471 pages, illustrated.

Cloth, \$1.75 net.

\section{Aikens' Training-School Methods and the Head Nurse}

This work not only tells how to teach, but also what should be taught the nurse and how much. The Medical Record says? "This book is original, breezy and healthy."

Hospital Training-School Methods and the Head Nurse. By CHARLOTTE A. Aikens, formerly Director of Sibley Memorial Hospital, Washington, D. C. 12mo of 267 pages.

Cloth, \$r.5o net.

\section{Aikens' Clinical Studies}

NEW (2d) EDITION

This work for second and third year students is written on the same lines as the author's successful work for primary students. Dietetic and Hygienic Gazette says there "is a large amount of practical information in this book."

Clinical Studies for Nurses. By Charlotte A. Aikens, formerly Director of Sibley Memorial Hospital, Washington, D. C. I2mo of ${ }_{569}$ pages, illustrated

Cloth, \$2.00 net 


\section{Böhm \& Painter's Massage}

The methods described are those employed in Hoffa's Clinic -methods that give results. Every step is illustrated, showing you the exact direction of the strokings. The pictures are large. You get the technic used in Professor Hoffa's Clinic.

Octavo of $9 \mathrm{r}$ pages, with 97 illustrations. Вy MAX ВонM, M. D., Berlin, Germany. Edited by Charles F. Painter, M. D., Professor or Orthopedic Surgery, Tufts College Medical School, Boston.

Cloth, \$r.75 net

\section{Grafstrom's Mechano-therapy SECOND Grafstrom's Mechano-therapy EDITION}

Dr. Grafstrom gives you here the Swedish system of mechanotherapy. You are given the effects of certain movements, gymnastic postures, medical gymnastics, general massage treatment, massage for the various conditions. The illustrations are full-page line drawings.

Mechanotherapy (Massage and Medical Gymnastics). By AxEL V. Grafstrom, B. Sc., M. D., Attending Physician Gustavus Adolphus Orphanage, Jamestown, New York. $16 \mathrm{mo}$ of 200 pages.

Cloth, \$r.25 net

\section{Friedenwald and Ruhrah's Dietetics for Nurses \\ NEW (3d) EDITION}

This work has been prepared to meet the needs of the nurse, both in training school and after graduation. American Journal of Nursing says it "is exactly the book for which nurses and others have long and vainly sought.."

Dietetics for Nurses. By Julius Friedenwald, M. D., Professor of Diseases of the Stomach, and JOHN RUhraH, M.D., Professor of Diseases of Children, College of Physicians and Surgeons, Baltimore. r2mo volume of $43 \mathrm{r}$ pages.

Cloth, $\$ 1.50$ net

\section{Friedenwald \& Ruhrah on Diet FOURTH}

This work is a fuller treatment of the subject of diet, presented along the same lines as the smaller work. Everything concerning diets, their preparation and use, coloric values, rectal feeding, etc., is here given in the light of the most recent researches.

Diet in Health and Disease. By Julius FRIEDENWALD, M.D., and John Ruhrah, M.D. Octavo volume of 85 ? pages. Cloth, $\$ 4.00$ net 


\section{Pyle's Personal Hygiene}

JUST OUT

NEW (6th) EDITION

Dr. Pyle's work discusses the care of the teeth, skin, complexion and hair, bathing, clothing, mouth breathing, catching cold; singing, care of the eyes, school hygiene, body posture, ventilation, heating, water supply, house-cleaning, home gymnastics, first-aid measures, etc.

A Manual of Personal Hygiene. Edited by Walter L. Pyle, M. D., Wills Eye Hospital, Philadelphia. 12mo, 543 pages of illus. \$r.50 net

\section{Galbraith's Personal Hygiene and Physical Training for Women \\ ILLUSTRATED}

Dr. Galbraith's book tells you how to train the physical powers to their highest degree of efficiency by means of fresh air, tonic baths, proper food and clothing, gymnastic and outdoor exercise. There are chapters on the skin, hair, development of the form, carriage, dancing, walking, running, swimming, rowing, and other outdoor sports.

Personal Hygiene and Physical Training for Women. By ANNA M. Galbraith, M.D., Fellow New York Academy of Medicine. 12 mo of 371 pages, illustrated.

Cloth, \$2.00 net

\section{Galbraith's Four Epochs of Woman's Life}

This book covers each epoch fully, in a clean, instructive way, taking up puberty, menstruation, marriage, sexual instinct, sterility, pregnancy, confinement, nursing, the menopause.

The Four Epochs of Woman's Life. By ANNA M. Galbraith, M. D. With an Introductory Note by JOHN H. MUSSER, M. D., University of Pennsylvania. $12 \mathrm{mo}$ of 247 pages.

Cloth, \$1.50 net

\section{Griffith's Care of the Baby NEw (6th) EDITION}

Here is a book that tells in simple, straightforward language exactly how to care for the baby in health and disease; how to keep it well and strong; and should it fall sick, how to carry out the physician's instructions and nurse it back to health again.

The Care of the Baby. By J. P. CROzer GRiffith, M.D., University of Pennsylvania. I2mo of 458 pages, illustrated. Cloth, $\$$ r.50 net 


\section{Hoxie \& Laptad's Medicine for Nurses}

Medicine for Nurses and Housemothers. By GEORGE, HowaRD HoxiE, M. D., University of Kansas; and PeARL L. Liaptad. 12 mo of 351 pages, illustrated. Cloth, $\$ 1.50$ net. New (2d) Edition.

This book gives you information that will heip you to carry out the directions of the physician and care for the sick in emergencies. It teaches you how to recognize any signs and changes that may occur between visits of the physician, and, if necessary, to meet conditions until the physician's arrival.

\section{Boyd's State Registration for Nurses}

State Registration for Nurses. By LouIE Croft BovD, R. N., Graduate Colorado Training School for Nurses. Octovo of 149 pages. Cloth, $\$ 1.25$ net. New (2d) Edition.

\section{Morrow's Immediate Care of Injured}

Immediate Care of the Injured. By ALBER'T S. MorRow, M. D., New York City Home for Aged and Infirm. Octavo of 354 pages, with 242 illustrations. Cloth, $\$ 2.50$ net.

New (2d) Edition.

\section{deNancrede's Anatomy}

NEW (7th) EDITION

Essentials of Anatomy. By CHARtes B. G. DENANCREDE, M. D., University of Michigan. 12mo of 400 pages, 180 illustrations.

Cloth, $\$ 1.00$ net.

\section{Morris' Materia Medica}

NEW (7th) EDITION

Essentials of Materia Medica, Therapeutics, and Prescription Writing. By HENRY MORRIS, M. D. Revised by W. A. BAST New York. $12 \mathrm{mo}$ of 300 pages, illustrated.

Cloth, $\$ 1.00$ net.

\section{Register's Fever Nursing}

A Text Book on Practical Fever Nursing. By EDwARD C. Register, M. D., North Carolina Medical College. Octavo of 350 pages, illustrated. Cloth, $\$ 2.50$ net. 



$$
\text { . }
$$





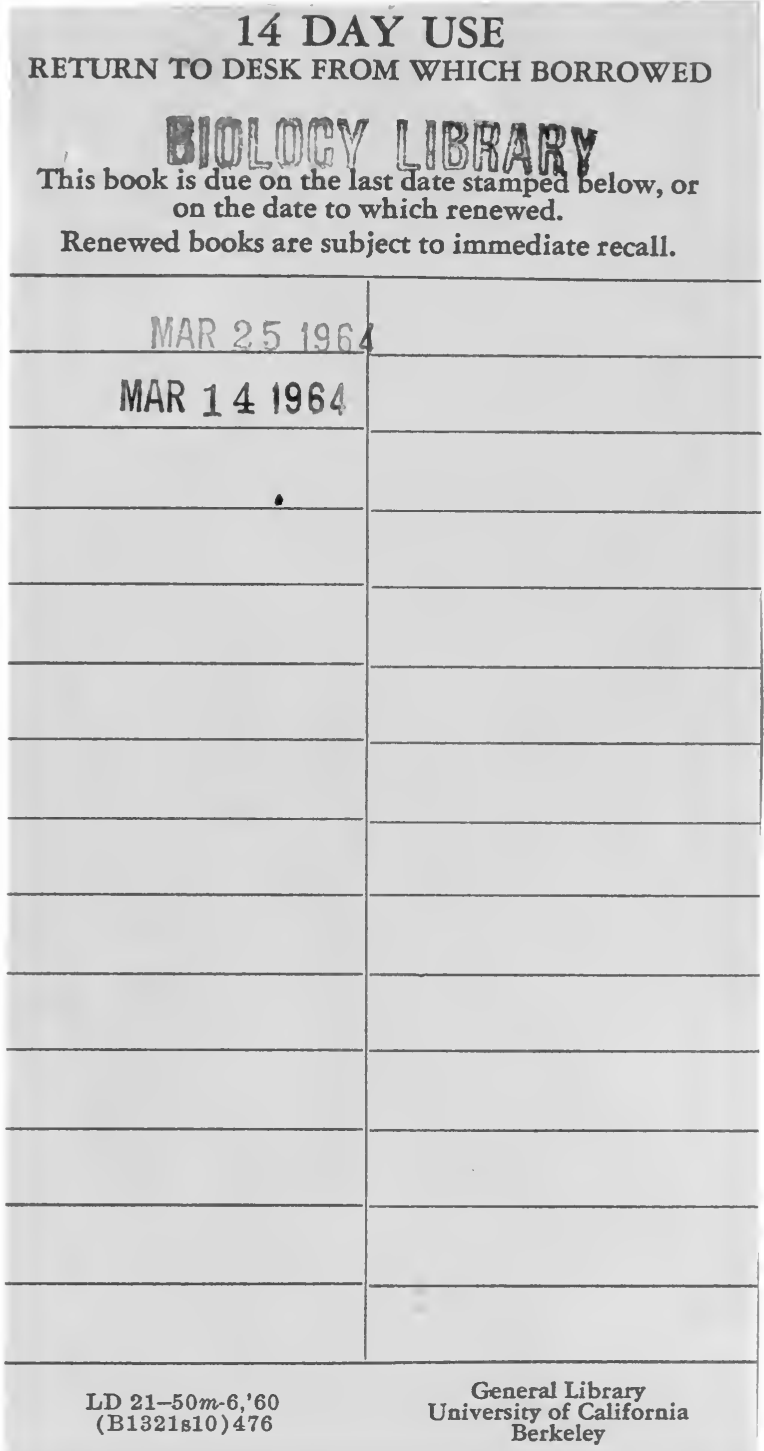


jun.....

Tho

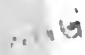

JU

$y^{2.2 x^{2}}+3$ 
